NBER WORKING PAPER SERIES

\title{
WHAT EXPLAINS THE STOCK MARKET'S REACTION TO FEDERAL RESERVE POLICY?
}

\author{
Ben S. Bernanke \\ Kenneth N. Kuttner \\ Working Paper 10402 \\ http://www.nber.org/papers/w10402
NATIONAL BUREAU OF ECONOMIC RESEARCH 1050 Massachusetts Avenue Cambridge, MA 02138 March 2004

Thanks to John Campbell for his advice; to Jon Faust, Refet Gürkaynak, Martin Lettau, Sydney Ludvigson, Athanasios Orphanides, Glenn Rudebusch, Brian Sack, Chris Sims, Eric Swanson, an anonymous referee and the associate editor of the Journal of Finance for their comments; and to Peter Bondarenko for research assistance. The views expressed here are solely those of the authors, and not necessarily those of the Federal Reserve System. The views expressed herein are those of the author(s) and not necessarily those of the National Bureau of Economic Research.

(C)2004 by Ben S. Bernanke and Kenneth N. Kuttner. All rights reserved. Short sections of text, not to exceed two paragraphs, may be quoted without explicit permission provided that full credit, including $\mathbb{C}$ notice, is given to the source. 
What Explains the Stock Market's Reaction to Federal Reserve Policy?

Ben S. Bernanke and Kenneth N. Kuttner

NBER Working Paper No. 10402

March 2004

JEL No. E44, G12

\section{ABSTRACT}

This paper analyzes the impact of changes in monetary policy on equity prices, with the objectives both of measuring the average reaction of the stock market and also of understanding the economic sources of that reaction. We find that, on average, a hypothetical unanticipated 25-basis-point cut in the federal funds rate target is associated with about a one percent increase in broad stock indexes. Adapting a methodology due to Campbell (1991) and Campbell and Ammer (1993), we find that the effects of unanticipated monetary policy actions on expected excess returns account for the largest part of the response of stock prices.

Ben S. Bernanke

Princeton University

and Board of Governors of the Federal Reserve System

bernanke@princeton.edu

Kenneth N. Kuttner

Oberlin College

Economics Department

10 North Professor Street, Rice Hall

Oberlin, OH 44074

and NBER

kenneth.kuttner@oberlin.edu 


\section{Introduction}

The ultimate objectives of monetary policy are expressed in terms of macroeconomic variables such as output, employment, and inflation. However, the influence of monetary policy instruments on these variables is at best indirect. The most direct and immediate effects of monetary policy actions, such as changes in the federal funds rate, are on the financial markets; by affecting asset prices and returns, policymakers try to modify economic behavior in ways that will help to achieve their ultimate objectives. Understanding the links between monetary policy and asset prices is thus crucially important for understanding the policy transmission mechanism.

This paper is an empirical study of the relationship between monetary policy and one of the most important financial markets, the market for equities. According to the conventional wisdom, changes in monetary policy are transmitted through the stock market via changes in the values of private portfolios (the "wealth effect"), changes in the cost of capital, and by other mechanisms as well. Some observers also view the stock market as an independent source of macroeconomic volatility, to which policymakers may wish to respond. For these reasons, it will be useful to obtain quantitative estimates of the links between monetary policy changes and stock prices. In this paper we have two principal objectives. First, we measure and analyze in some detail the stock market's response to monetary policy actions, both in the aggregate and at the level of industry portfolios. Second, we try to gain some insights into the reasons for the stock market's response.

Estimating the response of equity prices to monetary policy actions is complicated by the fact that the market is unlikely to respond to policy actions that were already anticipated. Distinguishing between expected and unexpected policy actions is therefore essential for discerning their effects. A natural way to do this is to use the technique proposed by Kuttner (2001), which uses federal funds futures data to construct a measure of "surprise" rate changes. ${ }^{1}$ To explain the economic reasons for the observed market response to policy

\footnotetext{
${ }^{1}$ Cochrane and Piazzesi (2002) proposed using the change in term eurodollar rates to measure policy surprises, while Rigobon and Sack (2002) utilized the eurodollar futures rate. While these measures provide informative gauges of interest rate expectations over a slightly longer horizon, Gürkaynak et al. (2002)
} 
surprises requires an assessment of how those policy surprises affect expectations of future interest rates, dividends, and excess returns. To do this, we adapt the procedure developed by Campbell (1991) and Campbell and Ammer (1993), which uses a vector autoregression (VAR) to calculate revisions in expectations of these key variables.

The results presented in section 2 of the paper show that the market reacts fairly strongly to surprise funds rate changes. Specifically, for a sample consisting of the union of days with a change in the target funds rate target and days of meetings of the Federal Open Market Committee (FOMC), we estimate that the CRSP value-weighted index registers a one-day gain of roughly one percent in response to a hypothetical surprise 25-basis-point easing. The market reacts little, if at all, to the component of funds rate changes that are anticipated by futures market participants. A comparable reaction is observed at a monthly unit of observation.

These results are broadly consistent with those of other studies which have looked at the link between monetary policy and the stock market. Thorbecke (1997), for example, documented a response of stock prices to shocks from an identified vector autoregression (VAR); in a similar vein, Jensen et al. (1996) and Jensen and Mercer (1998), examined the market's response to discount rate changes. This paper improves on these earlier efforts by using a measure of monetary policy based on futures data, which more cleanly isolates the unanticipated element of policy actions. In that sense, this paper resembles the more recent work of Rigobon and Sack (2002), who reported a significant response of the stock market to interest rate surprises derived from eurodollar futures. That paper's main innovation was the use of a novel, heteroskedasticity-based estimator to correct for possible simultaneity bias, an approach subsequently extended by Craine and Martin (2003). The analysis in this paper takes a more conventional event-study approach, while controlling directly for certain kinds of information jointly affecting monetary policy and stock prices. Section 2 also includes an assessment of the results' sensitivity to potential outliers, and an exploration of certain kinds of asymmetries in the market's response. Additional analysis distinguishes showed that federal funds futures are the best predictors of target funds rate changes one to five months ahead. 
between policy actions that affect the expected level of future interest rates, versus those that affect only the timing of rate changes.

Section 3 takes up the question of what explains equity prices' response, an issue not addressed by any of the papers cited above. The approach taken here is an adaptation of the VAR method proposed by Campbell (1991) and Campbell and Ammer (1993). The main finding is that policy's impact on equity prices comes predominantly through its effect on expected future excess equity returns. Specifically, we find that while an unanticipated rate cut (for example) generates an immediate rise in equity prices, it tends to be associated with an extended period of lower-than-normal excess returns. Some effect of policy on equity returns can be traced to revisions in cash flow forecasts, but very little is directly attributable to changes in expected real interest rates. One interpretation of this result is that monetary policy surprises are associated with changes in the equity premium, a point we discuss further below. But in the absence of a fully-developed asset pricing model, it is impossible to distinguish this interpretation from a simple market overreaction.

Relatively few papers to date have attempted to provide an explanation for the market's reaction to monetary policy. One effort along these lines is that of Patelis (1997), who also used the Campbell-Ammer framework to perform a decomposition similar to ours. Goto and Valkanov (2000) used a somewhat different VAR-based method to focus on the covariance between inflation and stock returns. Both relied on policy shocks derived from identified VARs, however, rather than the futures-based surprise used in our analysis. Boyd et al. (2001) also considered the linkage between policy and stock prices. Their analysis focused on the market's response to employment news, rather than to monetary policy directly, however. 


\section{The reaction of equity prices to changes in the target federal funds rate}

This section focuses on the immediate impact of monetary policy on equity prices, both for broad stock market indices and for industry portfolios. As noted in the introduction, however, one difficulty inherent in measuring policy's effects is that asset markets are forward looking and hence tend to incorporate any information about anticipated policy changes. Some effort is therefore required to isolate the unexpected policy change which might plausibly generate a market response. This does not say that asset prices respond to monetary policy only when the Fed surprises the markets, of course. Naturally, asset prices will also respond to revisions in expectations about future policy, which in turn may be driven by news about changing economic conditions. Our focus on unexpected policy actions allows us to circumvent difficult issues of endogeneity and simultaneity, and discern more clearly the stock market reaction to monetary policy.

One convenient, market-based way to identify unexpected funds rate changes relies on the price of federal funds futures contracts, which embody expectations of the effective federal funds rate, averaged over the settlement month. ${ }^{2}$ Krueger and Kuttner (1996) found that the federal funds futures rates yielded efficient forecasts of funds rate changes. Kuttner (2001) subsequently used these futures data to estimate the response of the term structure to monetary policy. The analysis in this section employs a similar method to gauge the response of equity prices to unanticipated changes in the federal funds rate from 1989 through 2002.

\subsection{Measuring the surprise element of policy actions}

A measure of the surprise element of any specific change in the federal funds target can be derived from the change in the futures contract's price relative to the day prior to the policy

\footnotetext{
${ }^{2}$ The contracts, officially referred to as "30 Day Federal Funds Futures," are traded on the Chicago Board of Trade. The implied futures rate is 100 minus the contract price.
} 
action. For an event taking place on day $d$ of month $m$, the unexpected, or "surprise" target funds rate change can be calculated from the change in the rate implied by the currentmonth futures contract. But because the contract's settlement price is based on the monthly average federal funds rate, the change in the implied futures rate must be scaled up by a factor related to the number of days in the month affected by the change,

$$
\Delta i^{u}=\frac{D}{D-d}\left(f_{m, d}^{0}-f_{m, d-1}^{0}\right)
$$

where $\Delta i^{u}$ is the unexpected target rate change, $f_{m, d}^{0}$ is the current-month futures rate and $D$ is the number of days in the month. ${ }^{3}$ The expected component of the rate change is defined as the actual change minus the surprise, or

$$
\Delta i^{e}=\Delta i-\Delta i^{u}
$$

Getting the timing right is, of course, crucial for event-study analysis. Before 1994, when the Fed instituted its current policy of announcing changes in the funds rate target, market participants generally became aware of policy actions on the day after the FOMC's decision, when it was implemented by the Open Market Desk. Following Rudebusch (1995) and Hilton (1994), we assign most pre-1994 rate changes to the date of the Desk's implementation. As documented in Kuttner (2003), however, the sample contains several minor deviations from this pattern. Six of these correspond to days on which the Desk allowed the funds rate to drift downward in advance (and presumably in anticipation) of the FOMC's decision, with the full awareness that its inaction would be interpreted as an easing of policy. A seventh exception occurred on December 18, 1990, when the Board of Governors made an unusual late-afternoon announcement of a cut in the discount rate,

\footnotetext{
${ }^{3}$ Because the monthly average of the effective federal funds rate on which the contract is based is very close to the average target rate, this method generally provides a good gauge of the surprise change in the target federal funds rate. In order to minimize the effect of any month-end noise in the effective funds rate, however, the unscaled change in the one-month futures rate is used to calculate the funds rate surprise when the change falls on one of the last three days of the month. Also, when the rate change occurs on the first day of the month, $f_{m-1, D}^{1}$ is be used instead of $f_{m, d-1}^{0}$. See Kuttner (2001) for details.
} 
from which market observers (correctly) inferred a 25-basis-point rate cut.

The policy of announcing target rate changes, which began in February 1994, eliminates virtually all of the timing ambiguity associated with rate changes in the earlier part of the sample. Moreover, because the change in the target rate is usually announced prior to the close of the futures market, the closing futures price generally incorporates the day's news about monetary policy. The only exception is October 15, 1998, when a 25-basis-point rate cut was announced after the close of the futures markets. In this case, the difference between the opening rate on the 16th and the closing rate on the 15th is used to calculate the surprise.

\subsection{Baseline event study results}

One approach to measuring the impact of Federal Reserve policy on the stock market is to calculate the market's reaction to funds rate changes on the day of the change. The market may of course also react to the lack of a change in the funds rate target, if a change had been anticipated. Because this approach involves looking at the response to specific events, it might be described as an "event-study" style of analysis. For the purpose of this paper, the relevant sample of events is defined as the union of all days when the funds rate target was changed, and days corresponding to FOMC meetings. The first "event" in the sample is the June 1989 25-basis-point rate cut, and the last corresponds to the FOMC meeting in December 2002. The 17 September 2001 observation is excluded from the analysis, as that day's rate cut occurred on the first day of trading following the September 11 terrorist attacks. Altogether, the sample contains 131 observations.

Table 1 presents a selection of descriptive statistics on the policy surprises and stock returns in our sample. The statistics are reported both for the pre-1994 period, when changes in the funds rate target were generally unannounced and frequently occurred between scheduled FOMC meetings, and the post-1994 period when all rate changes were announced, and most coincided with FOMC meetings. As measured by the standard deviation, the typical funds rate surprise in both periods is roughly 10 basis points; by contrast, 
equity prices are half again as volatile post-1994 as pre-1994. In both subsamples, equity returns are roughly ten percent more volatile on the monetary policy "event" days than on "non-event" days, consistent with policy actions inducing a market reaction of some kind.

Baseline estimates of the reaction of equity prices to monetary policy appear in Table 2. The results in column (a) of the table are based on a regression of the CRSP value-weighted return on the raw change in the federal funds rate target,

$$
H_{t}=a+b \Delta i_{t}+\varepsilon_{t}
$$

making no distinction between surprise and expected changes; $H_{t}$ represents the stock return, and $i_{t}$ is the funds rate target. The regression used for the results in column (b)

$$
H_{t}=a+b^{e} \Delta i_{t}^{e}+b^{u} \Delta i_{t}^{u}+\varepsilon_{t}
$$

distinguishes between expected and unexpected funds rate changes, $\Delta i_{t}^{e}$ and $\Delta i_{t}^{u}$, using the decomposition described above in section 2.1.

In both specifications, the error term $\varepsilon_{t}$ represents factors other than monetary policy that affect stock prices on event days. These factors are assumed to be orthogonal to the changes in the federal funds rate appearing on the right-hand side of the regression. Section 2.3 below discusses the validity of this assumption in some detail, and section 2.4 presents results that control directly for one observable source of endogeneity.

Although it has the expected negative sign, the response to the raw target rate change reported in column (a) of Table 2.2 is small and insignificant. When the target rate change is broken down into its expected and surprise components, however, the estimated stock market response to the latter is negative and highly significant: the results reported in column (b) imply a $-4.68 \%$ one-day return in response to a one percentage point surprise rate cut. ${ }^{4}$ The $R^{2}$ indicates that $17 \%$ of the variance in equity prices on these "event" days is associated with news about monetary policy. While Fed policy accounts for a nontrivial

\footnotetext{
${ }^{4}$ Very similar results are obtained using the S\&P 500 in place of the CRSP value-weighted return.
} 
portion of the variance of stock returns on event days, clearly it is far from the only piece of new information affecting stock returns.

The negative relationship between funds rate surprises and stock returns is readily visible in Figure 1. Also apparent, however, are a number of observations characterized by very large changes in equity prices — some exceeding three standard deviations in magnitude. This naturally raises the question of whether the results reported in the first two columns of Table 2 are sensitive to the inclusion of these observations.

To determine which observations might have an unduly large effect on the regression results, we computed influence statistics for each observation in the sample. These statistics are calculated from the quadratic form $\Delta \hat{b}_{t}^{\prime} \hat{\Sigma}^{-1} \Delta \hat{b}_{t}$, where $\Delta \hat{b}_{t}$ is change in the vector of regression coefficients resulting from dropping observation $t$, and $\hat{\Sigma}$ is the estimated covariance matrix of the coefficients. The distribution of these statistics, plotted in Figure 2, confirms that six observations, all with statistics in excess of 0.3 , exert an unusually large influence on the estimates; the comparable statistics for the remaining observations are all well below 0.2 and most are less than 0.05 . The six observations associated with the large influence statistics are labeled in Figure 1: 8 August 1991, 2 July 1992, 15 October 1998, 3 January 2001, 20 March 2001, and 18 April 2001. The first two of these are associated with events other than monetary policy actions, while the most recent four arguably represent unusual reactions to monetary policy actions. Each is in its own way is revealing.

All three of the candidate outliers occurring during the easing cycle that began in 2001 are classified as such because of their abnormally large reactions to the funds rate surprises. The unexpected 50-basis-point intermeeting rate reductions on 3 January and 18 April were both greeted euphorically, with one-day returns of $5.3 \%$ and $4.0 \%$ respectively. The 50basis-point rate cut on 20 March was received less enthusiastically, however. Even though the cut was more or less what the futures market had been anticipating, financial press reported that many equity market participants were "disappointed" the rate cut hadn't been an even larger 75 basis point action. Consequently, the market lost more than $2 \%$.

Another unusually vehement reaction to a Fed action is associated with the 25-basis- 
point intermeeting rate cut on 15 October 1998, which was taken in response to unsettled conditions in the financial markets - specifically, the deteriorating situations in Asia and Russia. For whatever reason, the unexpected intermeeting cut lifted equities over $4 \%$.

The stock market fell less than $0.3 \%$ on 2 July 1992 . What makes this reaction unusual, however, is the fact that it came on a day when the Fed unexpectedly cut the funds rate target by 50 basis points. The decision to cut was no doubt influenced by that day's unusually bleak employment report, in which reported payroll employment fell by 117 thousand. This raises the issue that some of the "surprise" rate changes in the sample may in fact represent endogenous responses to economic news, such as the employment report. This possibility is investigated in greater detail below in section 2.4.

The final candidate outlier is 21 August 1991, when the CRSP value-weighted index rose $2.7 \%$ on a day associated with an FOMC meeting. The futures market had apparently priced in some possibility of a rate cut on that day, but the FOMC's decision to leave rates unchanged generated a small, positive surprise. The financial press reported that the stock market jump was a response to the resolution of the attempted coup in Russia - clearly an event with no direct relation to that day's FOMC decision.

Two additional observations are highlighted in Figure 1: 17 May and 16 August 1994. While their relatively low influence statistics (0.05 and 0.04) do not qualify them as outliers, they stand out as unusual instances in which equities rose in spite of significant, positive funds rate surprises. As noted in Kuttner (2001), a similarly anomalous response is observed in the response of bond yields on those dates. The reason seems to be that both of these larger-than-expected 50-basis-point rate hikes were accompanied by statements by the FOMC suggesting that further rate increases were not imminent. This interpretation is consistent with the results reported below in section 2.6 indicating that the three-monthahead futures rates fell on the dates in question.

Columns (c) and (d) of Table 2 show the effect of dropping the six candidate outliers identified above. (The two observations from 1994 are retained.) The estimated response to funds rate surprises is still negative and significant, but smaller in magnitude: -2.55 , as 
opposed to -4.68 . The response to the expected component is smaller (and now no longer significant at the 0.05 level), as is the response to the raw funds rate change in column (c). Excluding the six outliers also decreases the $R$-squared from 0.17 to 0.05 .

\subsection{Orthogonality revisited}

As noted above, the event-study results reported in section 2.2 rely on the assumption that the error term is orthogonal to funds rate changes. One reason for a violation of this condition would be a contemporaneous response of monetary policy to the stock market. There are, however, no clear examples of instances in which a drop in equity prices led the FOMC to cut rates, or the inverse. Even in monthly data, evidence for such a systematic reaction is elusive. ${ }^{5}$ Moreover, to the extent the FOMC did respond in this way, it would tend to reduce the size of the estimated response to the funds rate surprise.

The orthogonality condition would also fail to hold if monetary policy and the stock market both responded jointly (and contemporaneously) to new information. For example, the release of data indicating weaker-than-expected economic growth would plausibly cause the stock market to decline, and make a cut in the funds rate target more likely. ${ }^{6}$ As in the case of a direct policy response to the stock market, the resulting tendency for rate cuts to be associated with stock market declines would lead to a downward bias in the size of policy's estimated market impact. A similarly attenuated reaction would be observed if surprise policy actions were thought to reveal private information about the state of the economy. ${ }^{7}$

Instances of direct, same-day policy responses to economic news are rare in our sample — at least in recent years, when the FOMC meeting schedule dictated the timing of most policy actions. During the pre-1994 subsample, however, it was not uncommon for the

\footnotetext{
${ }^{5}$ See, for example, Bernanke and Gertler (1999) and Fuhrer and Tootell (2003). Some evidence to the contrary was obtained by Rigobon and Sack (2003), however.

${ }^{6}$ The 17 September 2001 is an extreme example of just such a joint response: the Fed's 50 basis point rate cut and the stock market's sharp drop were both clearly spurred by the previous week's terrorist attacks.

${ }^{7}$ Romer and Romer (2000) suggested that such an information advantage could account for the bond market's response to monetary policy. However Faust et al. (2003) found little evidence to support this view.
} 
FOMC to cut rates on the heels of weaker-than-expected employment data. In fact, ten of the 23 rate cuts from June 1989 through July 1992 coincided with the release of the employment report. The analysis in section 2.4 below addresses this issue directly by allowing for a different market response on employment release days.

Recent studies have proposed two generic solutions to the endogeneity and jointresponse issues. One is to use intraday data in a relatively narrow "event window" surrounding the FOMC's announcement, thus distinguishing the impact of the policy change from the effects of news arriving earlier or later in the day. Applying this approach, Gürkaynak et al. (2004) reported, in work subsequent to ours, an equity price response that was virtually identical to that obtained from daily data. (Using intraday data did, however, result in a considerable improvement in the $R^{2}$.) Also in subsequent work, D'Amico and Farka (2003) uncovered a similar reaction using an approach incorporating intraday data in a VAR specification.

The other generic solution is more statistical in nature. Rigobon and Sack (2002), for example, used an estimator which, by exploiting the heteroskedasticity introduced by exogenous monetary policy actions, yields consistent estimates of the market's response. In a related approach, Craine and Martin (2003) developed a multivariate factor model that allows all asset prices to respond to common, unobserved information shocks. In the end, however, both studies report results that are very close to those obtained from event-study methods.

A correlation between the error term and the regressors in (4) could also arise if the regressors were measured with error. This possibility was explored by Poole et al. (2002) in the context of Treasury yields' response to monetary policy. They assumed the measurement error in the funds rate surprise was uncorrelated with other factors affecting yields, turning it into a classical errors-in-variables problem. To gauge the size of the measurement error, Poole et al. calculated the variance of the futures rate on days when the actual funds rate change was in line with the consensus market expectations reported by the Wall Street Journal; using this estimate, they found the attenuation in the bond market's response was 
typically on the order of five to ten percent.

Overall, the alternative econometric methods that have been used to correct for mismeasurement of the funds rate surprises uniformly yield results similar to those relying on the event-study methodology used in section 2.2. Moreover, to the extent that the event-study results are biased, that bias tends to understate the true response to monetary policy. Thus, it seems safe to proceed using the event-study approach, bearing in mind that it may yield slightly conservative estimates of the stock market's reaction to monetary policy.

\subsection{Employment releases and subsample stability}

This section investigates the robustness of the results reported in section 2.2 along two dimensions. One issue has to do with the joint response of monetary policy and the stock market to economic news. As noted above, ten funds rate cuts in the pre-1994 part of the sample occurred on the same day as the employment report. After 1994, with rate changes more or less dictated by the exogenous scheduling of FOMC meetings, this becomes less of an issue. As is evident in Figure 1, these observations are characterized by little, if any, correlation between the funds rate surprise and the stock return. In these instances, the "good news" for the stock market represented by the Fed's actions seems to have been almost exactly offset by the "bad news" about economic activity contained in the employment report.

Another issue concerns the stability of the estimated relationship. The avoidance of a same-day response to employment reports (and other economic news) is one possible reason the relationship might have changed in the early 1990s. The FOMC's practice of explicitly announcing rate changes, which began in February 1994, may also have altered the stock market's response to monetary policy.

To explore the possibility of different responses either post- 1994, or on days associated with employment releases, we interact the surprise rate change with dummy variables: one equal to 1 starting with the 4 February 1994 observation, and another equal to 1 on the days of pre-1994 employment releases. Table 3 reports the response of the CRSP value- 
weighted index to surprise rate changes in the presence of these interactive dummies. Like Table 2, columns (a) and (b) give the results for the full sample, and columns (c) and (d) give the results for the sample excluding the six candidate outliers identified above.

At first glance, the results in column (a) appear to show that the entire equity price response can be traced to the post-1994 period. The coefficient on the surprise itself is only -1.25 and insignificant; that on the surprise interacted with the post-1994 dummy is a highly significant -6.87 . This conclusion would be premature, however, as this regression neglects the possibility of endogeneity in the policy response prior to 1994. Including the surprise interacted with the employment release dummy as in column (b), increases the magnitude of the surprise response, and the positive interaction term implies a near-zero response to policy when it coincides with an employment release. These coefficients are statistically significant at only the 0.10 level however, and the post-1994 interaction term remains large and highly significant.

The significance of the post-1994 term is heavily influenced by the six outliers identified above, however. With those observations excluded, as in column (c), post-1994 rate surprises have only a slightly larger effect, and the difference is not statistically significant. The coefficient on the surprise itself -2.29 , and significant at the 0.05 level. But when the employment interaction term is included, the surprise coefficient grows to -3.57 . This effect is almost exactly offset for employment release days by the 3.33 coefficient on the interaction term. Both are now highly significant, and the post-1994 dummy remains insignificant. Thus, if the six candidate outliers are discarded as unrepresentative, there is no evidence of a break in 1994. Furthermore, the results confirm that the endogeneity problem discussed above reduces the OLS estimates of the market's response to policy surprises.

\subsection{Asymmetries}

Another set of questions concerns asymmetries, broadly defined: the possibility that the equity price response to monetary policy depends on the direction of the action, or on the context in which it occurred. As above in section 2.4, interactive dummy variables are used 
in the regression to investigate these questions.

One possibility is that the magnitude of the market's response depends the sign of the surprise. To allow for this, a dummy variable was set to 1 for those 37 observations with positive surprises. An interaction term involving this dummy and the surprise rate change was then included in the regression. The interactive term involving the employment release is also included, in order to pick up the smaller impact of funds rate surprises on employment release days. As above, the regressions are run with and without the six candidate outliers identified earlier. The results reported in Table 4 provide weak support at best for this form of asymmetry. For the full sample, in column (a) of the table, the coefficient on the interaction term indicates a smaller effect of positive surprises, but the difference is not statistically significant. There is virtually no difference for the no-outlier sample, shown in column (d).

A related kind of asymmetry can be modeled by including interactive dummies for rate changes associated with increases in the funds rate, and with surprises associated with no change in the funds rate. The full sample contains 14 observations of the former, and 76 of the latter. The results of this exercise appear in columns (b) and (e) of the table for the full and no-outlier samples. Again, the statistically insignificant coefficient in the rate increase interaction variable suggests the direction of movement is not an important determinant of the market's reaction. The positive and statistically significant estimated coefficient on the "no change" interaction variable does, however, indicate that the market responds very little, if at all, to policy "inactions." This presumably means that the failure to move at any specific FOMC meeting may be viewed largely as postponing the inevitable.

A third sort of asymmetry has to do with the context of the rate decision: whether it was taken at an FOMC meeting (109 observations), or represented a change in the direction of short-term interest rates (five observations). Interaction terms involving suitablyconstructed dummy variables are again used to capture possible differences in the market's response. The sign of the FOMC interaction term is unclear a priori. Decisions taken at FOMC meetings may be less subject to the sort of endogeneity issues discussed above, 
which would tend to increase the impact of rate changes on these days. On the other hand, intermeeting changes (at least those not associated with employment reports) may convey an urgency on the part of the FOMC which would tend to increase the size of the response. To the extent that interest rate reversals have a larger impact on expected future interest rates than other rate changes, these changes in the target federal funds rate would be expected to elicit a larger stock market response.

Columns (c) and (f) of Table 4 show the results from a regression that includes the FOMC and reversal interaction terms, along with employment report and post-1994 regressors. The coefficient on the surprise term remains an economically and statistically significant -3.97 for the full sample, and -3.67 for the no-outlier sample. In the full sample, the measured response is smaller on FOMC days; this difference disappears, however, when the candidate outliers are excluded. Reversals seem to have a large additional impact on the stock market: -6.33 for the full sample, and -17.62 for the no-outlier sample. In the latter case, the implausibly large estimate is driven almost entirely by the single observation in the southeast corner of Figure 1, corresponding to the first rate increase in 1994. Clearly, reversals in the direction of rate changes have occasionally been met with extreme market reactions, which accounts for the exaggerated response. With only five observations in the sample, however, inference on the additional stock market impact of reversals is hazardous at best. "Dummying out" these observations at least provides further confirmation that the baseline results are not dependent on the inclusion of these events.

Taken together, the results presented above confirm the existence of a strong one-day reaction of the stock market to unanticipated changes in federal funds rate. Just how strong this response is depends on whether the handful of potentially anomalous observations are viewed as representative, or discarded as outliers. The estimated response is stable over time, once the tendency for the FOMC to react to employment news in the early part of the sample is controlled for. The estimated reaction does, however, appear to be smaller (or nonexistent) for policy surprises associated with no change in the funds rate target. 


\subsection{Timing versus level surprises}

While the results presented above are consistent with a strong response of equity returns to funds rate surprises, that response is anything but uniform. In some cases, the reaction is muted, while in others the reaction seems out of proportion with the size of the measured surprise. One explanation for the lack of uniformity is that funds rate surprises differ in their impact on expected future short-term interest rates. Many of the surprises in the sample may have been interpreted as an advancement or postponement of a more-or-less inevitable change in policy, while others were viewed as altering the expected path of the funds rate for months to come. Surprises with a more durable on policy expectations would naturally tend to have a larger effect on equity prices than those which merely altered the timing of policy actions.

One way to gauge policy surprises' impact on expected future short-term rates is to examine the relationship between the surprises and the change in the fed funds futures rates in subsequent months. This relationship is depicted in Figure 3, which plots the change in the three-month-ahead futures rate against the funds rate surprise for the 131 observations in our June 1989 through December 2002 sample. The 45 degree line in the figure corresponds to a one-for-one response of the three-month futures rate to the current month funds rate surprise. Observations lying along a shallower line (i.e., those below the 45 degree line in the northeast quadrant and above in the southwest quadrant) are therefore those associated with a less than one-for-one effect on three-month-ahead expectations; those lying along a steeper line had a greater-than one-for-one effect. As noted above, the announcements accompanying the two rate hikes in May and August 1994 actually lowered three-month-ahead interest rate expectations, and as a result those two observations fall in the southeast quadrant.

Regressing the change in the three-month-ahead futures rate on the policy surprise yields an estimated slope coefficient of 0.65 , as shown in column (a) of Table 5. This suggests the impact of policy surprises on expectations is typically much less than one-forone; the difference is significant at the 0.01 level. A plausible interpretation of this result 
is that many of the unexpected funds rate changes in the sample are to a large extent surprises only with regard to the timing of policy actions. As shown in columns (b) through (d), FOMC meetings and "no change" surprises tend to be associated with an even smaller response of expectations.

In order to determine the extent to which differences in policy surprises' impact on expectations can help explain the stock market's response, our approach is to define a variable reflecting the difference between the surprises' effects on current and three-month-ahead interest rate expectations, and include this term in the equity return regressions. Specifically, our "timing surprise" variable is defined as the difference between the change in the three-month-ahead futures rate and the current funds rate surprise, i.e., the vertical distance from each observation to the 45 degree line in Figure 3. The timing surprise for an action with equal effects on current and expected future interest rates would thus be zero; those with a smaller effect on expected future interest rates would be negative. Results from the stock return regressions that include the timing surprise term appear in Table 6.

For comparison purposes, columns (a) and (c) of the table simply reproduce the baseline results reported earlier in Table 2, with and without the six candidate outliers. Columns (b) and (d) report the regression results when the timing surprise term is added to the regression. The inclusion of this term increases the magnitude of the coefficient on the current-month surprise, which goes from -4.68 to -6.20 for the full sample. Because this coefficient can now be interpreted as the impact of a funds rate surprise that changes expectations by the same amount (i.e., with the timing surprise equal to zero), this implies a larger stock price response to those policy surprises that affect the level of interest rates expected to prevail three months hence.

Similarly, the statistically significant, negative coefficient on the timing surprise term says that surprises with a less-than one-for-one impact on expectations (i.e., those for which the change in the three-month futures rate is smaller than the current-month surprise) have a correspondingly smaller effect on stock prices. In the extreme case of a "pure" timing surprise with no effect on the expected level of rates, the response is given by the difference 
between the two coefficients: -1.91 for the full and 0.09 for the no-outlier sample. (Neither is statistically significant at even the 0.10 level.) The results therefore show that policy actions affect stock returns only to the extent that they alter the expected level of rates in the months ahead.

\subsection{Results based on monthly data}

An alternative way to define the policy surprise is to focus on the expected change in policy at a regular, monthly horizon. Unlike the event study approach, the regular timing is amenable to the time series analysis employed below in section 3 to assess the causes of the market's response. It is worth noting that in this approach, any month could potentially contain a surprise policy action, and that a failure to change the funds rate target in any month could represent a policy surprise. Consequently, the monthly time-series approach is less susceptible to any sample selection issues that might arise in the context of the event-study methodology.

The use of monthly data calls for a slightly different gauge of unanticipated policy actions. Since the price of the federal funds futures contract is based on the monthly average federal funds rate, a natural definition of the month- $t$ surprise would be

$$
\bar{\Delta} i_{t}^{u} \equiv \frac{1}{D} \sum_{d=1}^{D} i_{t, d}-f_{t-1, D}^{1}
$$

where $i_{t, d}$ is the funds rate target on day $d$ of month $t$, and $f_{t-1, D}^{1}$ is the rate corresponding to the one-month futures contract on the last ( $D$ th) day of month $t-1 .^{8}$ The expected funds rate change is defined analogously as

$$
\bar{\Delta} i_{t}^{e} \equiv f_{t-1, D}^{1}-i_{t-1, D}
$$

The sum of the two is the average funds rate target in month $t$ minus the target on the last

\footnotetext{
${ }^{8}$ The settlement price of the federal funds futures contract is determined by the average over the calendar month, carrying the prior business day's rate over to weekends and holidays.
} 
day of month $t-1$. (The notation $\bar{\Delta}$ is used to distinguish this from the conventionallydefined first difference operator.)

This definition of the funds rate surprise raises a time aggregation issue. Measuring the surprise in terms of the average funds rate will tend to attenuate the size of the policy surprises, as discussed in detail in Evans and Kuttner (1998). Unfortunately, without making specific assumptions about the days of possible rate changes, there is no clean way to correct for this problem. ${ }^{9}$ Consequently, some caution is required when interpreting the magnitude of the surprises measured in this way. It is also important to note that the endogeneity issue discussed above in section 2.4 is almost certainly going to be more relevant to monthly funds rate surprises than it was for the day-ahead surprises. Rate changes that were unanticipated as of the end of the prior month may well include a systematic response to economic news, such as employment, output and inflation.

The results shown in Table 7 support the view that the month-ahead surprises incorporate an endogenous reaction to economic developments. The table reports the parameter estimates and $R^{2}$ from a regression of the monthly policy surprises on the surprise element of key economic reports, calculated as the difference between the number released and the consensus expectation for that number, compiled by Money Market Services. ${ }^{10}$ Over the full May 1989 through December 2002 sample, there appears to be a significant withinmonth impact of several data releases on the funds rate target: nonfarm payrolls, industrial production, retail sales, and core PPI, although these latter two have the "wrong" (i.e., negative) sign.

This relationship seems to be much stronger in the early part of the sample, however. The second column of the table shows the results for the same regression estimated from May 1989 through September 1992 (the date of the last rate cut associated with an employment report). The Fed's reaction to bad payroll employment news is now particularly pronounced. Moreover, the regression accounts for nearly half of the variance of the funds

\footnotetext{
${ }^{9}$ One solution would have been to assume that post-1994 rate changes were always expected to occur at scheduled FOMC meetings. The three intermeeting rate cuts in 2001 have made this assumption less plausible, however.

${ }^{10}$ We are indebted to Eric Swanson for his assistance with these data.
} 
rate surprises. By contrast, in the more recent February 1994 through December 2002 subsample, there is very little evidence of a within-month reaction to economic news, as shown in the third column of the table. Only retail sales is significant, and the regression now accounts for a much smaller share of the variance of funds rate surprises. ${ }^{11}$

Table 8 reports the results from a regression of the monthly CRSP value-weighted return the expected and unexpected components of monthly funds rate changes,

$$
H_{t}=a+b^{e} \bar{\Delta} i_{t}^{e}+b^{u} \bar{\Delta} i_{t}^{u}+\varepsilon_{t}
$$

Column (a) reports the estimates for the full sample, consisting of all 164 months from May 1989 through December 2002. As in the earlier results, there is a strong, statistically significant negative response to unanticipated rate increases, and little or no response to the anticipated actions. The $\overline{R^{2}}$ indicates that nearly $7 \%$ of the monthly stock return variance can be traced to unanticipated policy actions.

It is interesting to note that the magnitude of the response, -11.43 , is about twice that found in the event-study analysis. This difference in magnitudes is readily explained by the time aggregation issue alluded to earlier. In fact, if funds rate changes on average take place in the middle of the month (for example, if rate changes were distributed uniformly over the days of the month), then the magnitude of the estimated monthly surprises will be attenuated by one-half, which would explain the doubling of the estimated response of the stock price.

The negative relationship between policy surprises and stock returns is also evident in the scatterplot of the data in Figure 4. As in the daily data, a number of observations stand out as potential outliers, again raising the question of whether the results are sensitive to their inclusion. As above, influence statistics were calculated for each observation in the sample; those with statistics in excess of 1.5 are flagged as outliers in the plot. (The most

\footnotetext{
${ }^{11}$ Again, retail sales is significant with the "wrong" sign. But this result is due entirely to an anomalous $7 \%$ jump in retail sales in November 2001, which happened to occur in a month in which the Fed also cut the funds rate target.
} 
conspicuous of these is the data point deep in the southwest quadrant, which corresponds to September 2001.) Dropping these ten observations makes little difference to the results, however. In fact, as shown in column (b) of Table 8, the estimated coefficient of -14.26 is somewhat larger than it is for the full sample, and the $\overline{R^{2}}$ rises to 0.096 .

The monthly data contain very little evidence for the sorts of asymmetries uncovered in the daily data. As shown in columns (c) and (d), there is no indication that the stock price response depends on the sign of the surprise, or on the direction of the rate change. Nor is there any evidence of a different response to policy reversals, or to the MMS employment surprises. $^{12}$

We have so far focused on the responses of broad equity indexes, but of course it is also possible to examine the responses of more disaggregated indexes. Table 9 reports estimates of (7) for the ten industry portfolios constructed from CRSP returns as in Fama and French (1988). ${ }^{13}$ The most responsive industries are high tech and telecommunications, with coefficients half again as large that for the overall value-weighted index. On the other end of the spectrum, energy and utilities are only half as responsive as the overall market, and the relevant coefficients are statistically insignificant. ${ }^{14}$ The low $R^{2}$ s indicate that very little of those industries' variance is associated with unexpected policy actions. The estimates' precision is, however, not sufficient to reject the hypothesis of an equal reaction for all 10 industries.

A natural question is the degree to which the pattern of responses of industry portfolios is consistent with the implications of the CAPM — that is, whether the observed responses are proportional to the industries' market "betas". A straightforward way to address this question is to obtain industry betas from a regression of the excess return in industry $i, y_{i, t}$,

\footnotetext{
${ }^{12}$ Interestingly, the employment surprise is negative and significant in a univariate regression (not reported), but becomes insignificant once the federal funds surprise is included. This is consistent with the findings of Boyd et al. (2001), and corroborates their conjecture that the policy response accounts for equities' perverse response.

${ }^{13}$ The Fama-French portfolio data are available from mba.tuck.dartmouth.edu/pages/faculty/ken.french.

${ }^{14}$ Using methods similar to ours, Guo (2002) found that the impact of monetary policy on stock prices does not seem to depend on firm capitalization.
} 
on the market excess return, $y_{M, t}$,

$$
y_{i, t}=\alpha+\beta_{i} y_{M, t}+v_{t}
$$

estimated on the same May 1989 to December 2002 sample used to estimate the response to monetary policy. ${ }^{15}$ The industry response implied by the CAPM can then be expressed as:

$$
\hat{b}_{i}^{u}=\hat{\beta}_{i} \times \hat{b}^{u}
$$

where $\hat{b}^{u}$ is the estimated response of the CRSP value-weighted excess return to funds rate surprises.

Figure 5 plots these fitted responses to monetary policy against the estimated responses, $\hat{b}_{i}^{u}$, reported in Table 9, along with the $80 \%$ confidence intervals associated with those estimates. Also plotted is the 45-degree line that the points would lie on if the CAPM perfectly accounted for variation across industries. Although the fit is not perfect, the points line up reasonably well along the 45-degree line, suggesting that the one-factor CAPM does a good job of explaining the observed industry variation. High-tech's measured sensitivity to monetary policy is in fact somewhat less than its beta would imply, while telecommunications' is somewhat greater. On the other end of the spectrum, the utilities and energy industries' low market betas for the most part account for their muted response to monetary policy. The CAPM-implied response represented by the 45-degree lies within the confidence intervals associated with the estimated responses, although given the imprecision of those estimates, this is clearly not a powerful test.

\footnotetext{
${ }^{15}$ Using betas based on the sum of contemporaneous and lagged market covariances, as in Campbell and Vuolteenaho (2003), makes virtually no difference to the results. Campbell and Vulteenhaho's proposed two-factor decomposition also yields very similar results to those reported in the text.
} 


\section{Policy, fundamentals and stock prices}

Having documented the reaction of equity returns to Federal Reserve policy in section 2 above, we now turn to the more difficult question of what explains the observed reaction. There are three broad reasons why an unexpected funds rate increase may lead to a decline in stock prices: it may be associated with a decrease in expected future dividends, a rise in the future expected real interest rates used to discount those dividends, or an increase in the expected excess returns (i.e., the equity premiums) associated with holding stocks. Simple regressions of equity returns on surprise changes in the federal funds rate are silent on the question, so a more structured approach is required to disentangle the various effects.

The approach of this paper is an adaptation of the method used by Campbell (1991), and Campbell and Ammer (1993). In brief, their method uses a log-linear approximation to decompose excess equity returns into components attributable to news about real interest rates, dividends, and future excess returns, then employs a VAR methodology to obtain proxies for the relevant expectations. ${ }^{16}$ We take the Campbell-Ammer framework one step further, however, by relating the proxies for expectations to the news about the path of monetary policy embodied in the surprises derived from federal funds futures. This allows us to estimate the impact of federal funds surprises on expected future dividends, real interest rates, and expected future excess returns. It turns out that the largest effects come from revisions to expectations of future excess returns, and to expectations of future dividends. Real interest rates have a very small direct impact.

The object of this analysis is the (log) excess return on equities, denoted $y_{t+1}$. This is defined as the total return on equities (price change plus dividends), minus the risk-free rate (the one-month Treasury bill yield). The return dated $t+1$ is measured over period $t$, i.e., from the beginning of period $t$ to the beginning of period $t+1$. Let $e_{t+1}^{y}$ represent the unexpected (relative to expectations formed at the beginning of period $t$ ) excess return during period $t$, i.e., $y_{t+1}-E_{t} y_{t+1}$.

\footnotetext{
${ }^{16}$ Because VARs require periodic time series data, the subsequent analysis will use the monthly measure of the funds rate surprises.
} 
Using the linearization developed by Campbell and Shiller (1988), we can express the period $t$ unexpected excess return on equity in terms of the revision the expectation of discounted future dividends, the real interest rate, and future excess returns. (A sketch of the derivation can be found in the appendix.) The decomposition can be written as:

$$
e_{t+1}^{y}=\tilde{e}_{t+1}^{d}-\tilde{e}_{t+1}^{r}-\tilde{e}_{t+1}^{y}
$$

where the $e$ represent the revision in expectations between periods $t$ and $t+1$, and the tilde denotes a discounted sum, so that

$$
\begin{aligned}
& \tilde{e}_{t+1}^{d}=\left(E_{t+1}-E_{t}\right) \sum_{j=0}^{\infty} \rho^{j} \Delta d_{t+1+j} \\
& \tilde{e}_{t+1}^{r}=\left(E_{t+1}-E_{t}\right) \sum_{j=0}^{\infty} \rho^{j} r_{t+1+j} \\
& \tilde{e}_{t+1}^{y}=\left(E_{t+1}-E_{t}\right) \sum_{j=1}^{\infty} \rho^{j} y_{t+1+j} .
\end{aligned}
$$

The discount factor $\rho$, which comes out of the linearization, represents the steady-state ratio of the equity price to the price plus dividend; following Campbell and Ammer (1993), this is set to 0.9962 . As emphasized by Campbell (1991), (10) is really nothing more than a dynamic accounting identity relating the current excess return to revisions in expectations. As such, it contains no real economic content, much less any specific asset pricing model; such a model would be required to provide a link between the conditional expectations of future returns and economic variables (e.g., consumption).

Implementing this decomposition requires empirical proxies for the expectations appearing in (10). The approach of Campbell (1991) and Campbell and Ammer (1993) is to model expectations using a Vector Autoregression (VAR) involving the variables of interest (excess returns and the real interest rate) along with any other indicators that might be helpful in forecasting those variables. Calculating the discounted sum of the revisions in expectations is straightforward; to do so involves writing the $n$ variable, $p$ lag VAR as a 
first-order system,

$$
z_{t+1}=A z_{t}+w_{t+1}
$$

where $z_{t+1}$ is an appropriately stacked $n p \times 1$ vector containing the excess equity return, the real interest rate, and any additional indicators. With the VAR expressed in this form, the ingredients of (10) are given by

$$
\begin{aligned}
& e_{t+1}^{y}=s_{y} w_{t+1}, \\
& \tilde{e}_{t+1}^{y}=s_{y} \rho A(1-\rho A)^{-1} w_{t+1}, \\
& \tilde{e}_{t+1}^{r}=s_{r}(1-\rho A)^{-1} w_{t+1} \text { and } \\
& \tilde{e}_{t+1}^{d}=e_{t+1}^{y}+\tilde{e}_{t+1}^{y}-\tilde{e}_{t+1}^{r},
\end{aligned}
$$

where $s_{y}$ and $s_{r}$ are appropriate $1 \times n p$ selection matrices.

Two features of the Campbell-Ammer method deserve further comment. One is its parametric approach to constructing long-horizon expectations of stock returns: one has to assume that the dynamics of equity returns many years in the future are adequately captured by a parsimonious VAR model. To a large extent, this parametric approach is forced upon us, as the relatively short experience with federal funds futures is not sufficient to directly estimate the long-horizon impact on stock asset returns, particularly in light of the questionable small-sample properties of long-horizon regressions (see Nelson and Kim (1993)). But as discussed below, the use of the VAR does allow us to estimate the dynamics of stock returns over a longer sample than the period for which futures data are available.

A second important feature of the approach is that dividends are not included explicitly as a variable to be forecast; given $e_{t+1}^{y}, \tilde{e}_{t+1}^{y}$ and $e_{t+1}^{r}, e_{t+1}^{d}$ is backed out from (10). In principle, it would be possible to forecast dividends directly in the VAR, and instead back out an implied $\tilde{e}_{t+1}^{y}$. In practice, however, this is complicated by a strong seasonal pattern, and a root near unity in the dividend process. It is important to note that to the extent that the VAR understates the predictability of excess returns, treating dividends as a residual means 
that the method will end up attributing too much of the return volatility to dividends. ${ }^{17}$

\subsection{The forecasting VAR}

The first step is to set up a VAR to capture the dynamic correlations between the excess equity return and the real interest rate (calculated as the one-month bill yield minus the log difference in the non-seasonally-adjusted CPI). The VAR must therefore include these two variables at a minimum, plus whatever other variables that might be useful in forecasting them. (One important constraint, of course, is that these variables are available in real time.) We follow Campbell and Ammer (1993) in using a six-variable one-lag system that included, besides the real rate and equity return: the relative bill rate (defined as the three-month bill rate minus its 12-month lagged moving average), the change in the bill rate, the (smoothed) dividend price ratio, and the spread between the 10-year and onemonth Treasury yields. For comparability with the Campbell-Ammer (1993) results, we use January 1973 as the starting date for estimation.

\subsection{A variance decomposition of equity returns}

Equation (10) expresses the current month's excess equity returns into three components, which may be correlated with one another. The variance of the current excess return can therefore be broken down into the sum of the three variances, plus (or minus) the relevant three covariances,

$$
\begin{aligned}
\operatorname{Var}\left(e_{t+1}^{y}\right)= & \operatorname{Var}\left(\tilde{e}_{t+1}^{d}\right)+\operatorname{Var}\left(\tilde{e}_{t+1}^{r}\right)+\operatorname{Var}\left(\tilde{e}_{t+1}^{y}\right)- \\
& 2 \operatorname{Cov}\left(\tilde{e}_{t+1}^{d}, \tilde{e}_{t+1}^{r}\right)-2 \operatorname{Cov}\left(\tilde{e}_{t+1}^{d}, \tilde{e}_{t+1}^{y}\right)+2 \operatorname{Cov}\left(\tilde{e}_{t+1}^{y}, \tilde{e}_{t+1}^{r}\right),
\end{aligned}
$$

giving a sense of the relative contributions of news about real interest rates, dividends, and expected future excess returns to fluctuations in the current excess return. The results of this

\footnotetext{
${ }^{17} \mathrm{~A}$ useful check on the Campbell-Ammer procedure would be to compare its implied dividend forecasts with the observed behavior of dividends. Such a comparison is beyond the scope of the present paper, however.
} 
decomposition appear in Table 10. For comparison, the table displays results for the full 1973-2002 sample and for the subsample beginning in May 1989, when the federal funds futures data became available. The columns labeled "total" show the total contribution, and those labeled "share" expresses that contribution as a percentage of the excess return variance, i.e., normalizing by $\operatorname{Var}\left(e_{t+1}^{y}\right)$.

The results for the full 1973-2002 sample are similar to those reported by Campbell and Ammer (1993) for their 1973-87 sample. In particular, the variance in expected future excess returns accounts for the majority of the variance of the current equity return: $76 \%$, compared with Campbell and Ammer's 101\%. Dividends make a correspondingly larger contribution of $24.5 \%$, as opposed to Campbell and Ammer's 14\%. In both cases, the contribution of the real interest rate is negligible ( $0.3 \%$ and $3 \%$ respectively) and statistically insignificant.

The 1989-2002 subsample yields somewhat different results, as shown in the right-hand portion of the table. Considerably less variance is attributed to revisions in expectations of future excess returns, and the dividend component now plays a somewhat larger role. The main reason for this seems to be a decline in the forecastability of equity returns in recent years, consistent with the observed fall in the adjusted $R$-squared from 0.04 to basically zero. With returns less forecastable, the Campbell-Ammer methodology by default assigns more of the excess return variance to dividend news.

\subsection{The effects of federal funds surprises}

The most straightforward way to analyze the impact of monetary policy within the framework introduced above is to include the federal funds surprises in the VAR as an exogenous variable

$$
z_{t+1}=A z_{t}+\phi \bar{\Delta} i_{t+1}^{u}+w_{t+1}^{\perp}
$$

where $\phi$ is an $n \times 1$ vector capturing the contemporaneous response of the elements of $z_{t+1}$ to the unanticipated rate change period $t+1$. The new disturbance term $w_{t+1}^{\perp}$ is 
by construction orthogonal to the funds rate surprise. This effectively breaks the VAR's one-month-ahead forecast error into a component having to do with news about monetary policy, $\phi \bar{\Delta} i_{t+1}^{u}$ and a component incorporating information about things other than policy.

Because $\Delta i_{t+1}^{u}$ represents a prediction error from a rational forecast made at time $t$, it should be orthogonal to $z_{t}{ }^{18}$ Consistent estimates of both $A$ and $\phi$ can therefore be obtained by first estimating the VAR's parameters, and then regressing the VAR's one-step-ahead forecast errors on the funds rate surprises. Normally, there would be no advantage to the two-step procedure over simply estimating (15) directly. But in our case, using the two-step procedure allows us to estimate the VAR dynamics (i.e., the coefficients in the $A$ matrix) over a sample longer than the period for which federal funds futures are available. ${ }^{19}$ The longer sample will of course tend to improve the estimates' precision.

\subsubsection{The dynamic response to funds rate surprises}

Incorporating the federal funds surprises into the VAR in this way allows us to do two things. First, because it extracts an orthogonal element from the $w_{t}$ forecast error, we can use it to calculate the dynamic responses of the variables in the VAR to the orthogonal component. The $k$-month response to a one-percentage-point surprise increase in the funds rate can be calculated quite simply as $A^{k} \phi$.

An obvious question to arise at this point concerns the relationship between these futures-based funds rate surprises and the more familiar monetary policy shocks derived from an identified VAR. The methods used to construct the one-month-ahead funds rate forecasts differ, of course, with one using the futures market's implicit forecast, and the other using a reduced-form econometric model. Forecast methodologies aside, however, the orthogonalization procedure described above is conceptually equivalent to ordering the federal funds rate first in a VAR system. Since this precludes any contemporaneous re-

\footnotetext{
${ }^{18}$ Krueger and Kuttner (1996) showed that in practice, the federal funds futures prediction errors are generally uncorrelated with lagged information.

${ }^{19}$ Faust et al. (2002) used a similar procedure. Specifically, they estimate the VAR parameters over the full sample, but choose an orthogonalization based on the response of interest rates over the post-1989 subsample.
} 
action of the funds rate to economic news, the surprises calculated in this way may well incorporate an endogenous policy response to information arriving within the month. Consequently, the impulse responses may represent the effects of things other than monetary policy per se.

One way to minimize this problem would be to purge the futures-based funds rate surprises of any contemporaneous response to the economy by projecting them onto the relevant information variables, such as the data news obtained from the MMS survey. Alternatively, since the results above in section 2.7 indicate there has been little, if any, correlation between the funds rate surprises and data news since 1994, the $\phi$ estimated only on the post-1994 subsample should be relatively free from this endogeneity problem. This is the approach taken in the results presented below.

The upper-left-hand panel of Figure 6 displays the dynamic response of excess returns calculated in this way. The initial decline of $11.6 \%$ (not shown, because of the difference in scale) is followed by another month of negative returns, and then by several months of near-zero excess returns. ${ }^{20}$ After six months, equities begin to exhibit small positive excess returns, peaking at $0.16 \%$ per month $(1.9 \%$ at an annual rate), and continuing for a period measured in years.

The contractionary funds rate surprise also leads to a sizable increase in the relative bill rate, which persists several months (essentially by construction). The real T-bill rate rises sharply at first, but the increase is relatively short-lived, and all but disappears after four months. In the near term, the dynamics of equity excess returns are dominated by the effects of rising interest rates. But as these effects die out, the long-run effect of the dividend-price ratio, which rises as a result of the fall in equity prices, reasserts itself. This leads to the highly persistent, positive excess returns visible in the impulse response function.

\footnotetext{
${ }^{20}$ This $11.6 \%$ response differs slightly from the results in section 2.7 because the dependent variable is the forecast error in the log excess return, rather than the raw nominal return.
} 


\subsubsection{Explaining the stock market's reaction to Fed policy}

The second thing this approach allows us to do is calculate the impact of the federal funds surprises on the discounted sums of expected future excess returns, interest rates, and dividends. And since it is these sums that are related to the current excess return through (10), this provides a natural way to determine the source (or sources) of the stock market's reaction to monetary policy.

One way to assess policy's effect on these discounted sums is simply to use the VAR to calculate $\tilde{e}_{t+1}^{d}, \tilde{e}_{t+1}^{r}$, and $\tilde{e}_{t+1}^{y}$, which represent the revisions in expectations of the relevant present values, and regress these variables in turn on $\Delta i_{t+1}^{u}$. Although this would provide the answer we are after, the standard errors would be misleading, as they would fail to take into account the dependence of the $\tilde{e}$ s on the estimated parameters of the VAR.

An alternative way to do the same calculation is to write out the $\tilde{e}$ s in terms of the VAR coefficients. Taking $\tilde{e}_{t+1}^{y}$ as an example:

$$
\begin{aligned}
\tilde{e}_{t+1}^{y} & =s_{y} \rho A(1-\rho A)^{-1} w_{t+1} \text { or } \\
& =s_{y} \rho A(1-\rho A)^{-1}\left(\phi \bar{\Delta} i_{t+1}^{u}+w_{t+1}^{\perp}\right) .
\end{aligned}
$$

The response of the present value of expected future excess returns to the federal fundsrate surprise is just

$$
s_{y} \rho A(1-\rho A)^{-1} \phi
$$

Thus, the response of expected future excess returns depends not only on the $\phi$ vector, but also on the VAR dynamics represented by $A$. Similarly, the response of the present value of current and expected future real returns is

$$
s_{r}(1-\rho A)^{-1} \phi
$$


and the implied response of the present value of current and expected future dividends is

$$
s_{y} \phi+s_{y} \rho A(1-\rho A)^{-1} \phi+s_{r}(1-\rho A)^{-1} \phi
$$

or alternatively

$$
\left(s_{y}+s_{r}\right)(1-\rho A)^{-1} \phi
$$

The standard errors for these responses are calculated using the delta method, as in Campbell and Ammer (1993).

The results of these calculations appear in Table 11. With the VAR estimated over the entire 1973-2002 sample, funds rate surprises have a large, marginally significant impact on the discounted sum of future excess returns, accounting for just over half of the contemporaneous response excess returns, equal to -11.55 . The reason for this large contribution is readily understood in terms of the impulse responses plotted in Figure 6. Though small, funds rate shocks are estimated to have a highly persistent positive effect on excess returns. Discounting these future positive excess returns back using a discount factor near unity yields a large negative impact on the current excess return. The -4.82 impact of funds rate surprises on dividends is nearly as large as that of future excess returns, and it too is significant at the 0.10 level. The impact on the discounted sum of real rates is very small, however, accounting for less than one percentage point of the excess return response.

The results are qualitatively similar when the VAR is estimated over the shorter 19892000 sample. The only noteworthy difference is the smaller impact on expected future excess returns, which now account for a statistically insignificant 3.29 percentage points of the $-11.01 \%$ response. The reason for this can be traced to the smaller amount of longrun forecastability in excess returns in the post-1989 sample. In fact, the impulse response functions from this truncated sample (not shown) are nearly identical to those for the full 1973-2002 sample, shown above. The main difference is that the response of the excess return is negligible after six months or so, and it is this difference that accounts for the smaller contribution of future excess returns. 


\section{Conclusions}

This study has documented a relatively strong and consistent response of the stock market to unexpected monetary policy actions, using federal funds futures data to gauge policy expectations. For broad stock market gauges like the CRSP value-weighted index, an unexpected 25-basis-point rate cut would typically lead to an increase in stock prices on the order of one percent. The result is robust to the exclusion of outliers and to the choice of windows for measuring the stock market's response. There is some evidence of a larger market response to policy changes that are perceived to be relatively more permanent, and a smaller response to unexpected inaction on the part of the FOMC. We also find that reactions to monetary policy surprises tend to differ across industry-based portfolios, with the high-tech and telecommunications sectors exhibiting a response half again as large as that of the broad market indices. Other sectors, such as energy and utilities, seem not to be significantly affected by monetary policy. The industry responses to monetary policy changes seem broadly consistent with the predictions of the standard CAPM.

Although we have found an effect of monetary policy on the stock market of reasonable size, we should emphasize that monetary policy surprises are responsible for only a small portion of the overall variability of stock prices. Our method also does not allow us to determine the role played by anticipated monetary policy in stock price determination. Stocks are claims to real assets, so if monetary neutrality holds stock values should be independent of monetary policy in the very long run. In the medium term, however, real and nominal volatility induced by the form of the monetary policy rule may well influence stock values.

A more difficult question is why stock prices respond as they do to monetary policy. We have tried to make progress on this question by asking whether monetary policy affects stock values through its effects on real interest rates, expected future dividends, or expected future stock returns. The results presented in this paper showed, perhaps surprisingly, that the reaction of equity prices to monetary policy is, for the most part, not directly attributable to policy's effects on the real interest rate. This finding is the result of the 
relatively transitory movements in real interest rates induced by surprise policy actions. Instead, the impact of monetary policy surprises on stock prices seems to come either through its effects on expected future excess returns or on expected future dividends. (The exact breakdown between these two channels depends somewhat on the choice of sample, which appears to affect the long-horizon forecastability of excess returns.)

Economically, how should we interpret the result that monetary policy affects stock prices in significant part by affecting expected excess returns? Taken literally, this result suggests that tight money (for example) lowers stock prices by raising the expected equity premium. This could come about in at least two ways. First, tight money could increase the riskiness of stocks directly, for example, by raising the interest costs or weakening the balance sheets of publicly owned firms. Second, tight money could reduce the willingness of stock investors to bear risk, for example by reducing expected levels of consumption, as in Campbell and Cochrane (1999), or because of its association with higher inflation, as in Brandt and Wang (2003). These linkages open up the possibility of new ways in which monetary policy may affect real activity - for example, by affecting the level of precautionary saving.

An alternative interpretation of our results is that the large movements in excess returns associated with monetary policy changes reflect excess sensitivity or overreaction of stock prices to policy actions. A more tightly structured analysis that encompasses a wider class of assets may help to differentiate these interpretations. In any case, further exploration of the link between monetary policy and the excess return on equities is an intriguing topic for future research. 


\section{Appendix: deriving equation 10}

This appendix provides a brief sketch of the derivation of the log-linearized relationship between the current excess return, expected future excess returns, dividend growth, and real interest rates given in (10). The derivation roughly follows Campbell and Shiller (1988) and Campbell (1991).

The starting point is simply the definition of the stock return, $H_{t+1}$ :

$$
1+H_{t+1} \equiv \frac{P_{t+1}+D_{t}}{P_{t}}
$$

where $P$ is the stock price and $D$ is the dividend. Taking logs and letting $h_{t+1}=\ln \left(1+H_{t+1}\right)$ yields:

$$
h_{t+1}=\ln \left(P_{t+1}+D_{t}\right)-\ln \left(P_{t}\right) \text {. }
$$

The next step is to derive a $\log$-linear approximation to $\ln \left(P_{t+1}+D_{t}\right)$. One way to do this is to first-difference, and express the change in the log of the sum as the weighted sum of the log differences

$$
\Delta \ln \left(P_{t+1}+D_{t}\right) \approx \rho \Delta p_{t+1}+(1-\rho) \Delta d_{t}
$$

where $\rho$ is the steady-state $P /(D+P)$. "Integrating" this expression gives

$$
\ln \left(P_{t+1}+D_{t}\right) \approx k+\rho p_{t+1}+(1-\rho) d_{t}
$$

substituting this into the expression for $h_{t+1}$, substituting $\delta_{t}$ for $d_{t-1}-p_{t}$, and combining terms gives

$$
\begin{aligned}
h_{t+1} & \approx k-\rho \delta_{t+1}+\delta_{t}+\Delta d_{t} \\
& \approx k+\left(1-\rho L^{-1}\right) \delta_{t}+\Delta d_{t}
\end{aligned}
$$

The next step is to solve forward, giving

$$
\begin{aligned}
\delta_{t} & =\left(1-\rho L^{-1}\right)^{-1}\left(h_{t+1}-\Delta d_{t}-k\right) \\
& =\sum_{i=0}^{\infty} \rho^{i}\left(h_{t+1+i}-\Delta d_{t+i}\right)-k /(1-\rho)
\end{aligned}
$$


Substituting this, and a similar expression for $\delta_{t+1}$, into (5) and collecting terms yields:

$$
h_{t+1}-E_{t} h_{t+1}=-\sum_{i=1}^{\infty} \rho^{i}\left(E_{t+1}-E_{t}\right) h_{t+1+i}+\sum_{i=0}^{\infty} \rho^{i}\left(E_{t+1}-E_{t}\right) \Delta d_{t+1+i}
$$

which corresponds to equation 1 in Campbell (1991).

A breakdown of excess returns can then be derived by expressing the equity return $h_{t+1}$ as the sum of a risk-free rate and an excess return

$$
h_{t+1}=r_{t+1}+y_{t+1}
$$

Because it is assumed that $r_{t+1}$ is known at time $t$, the "excess return surprise" $y_{t+1}-E_{t} y_{t+1}$ is the same as the overall return surprise $h_{t+1}-E_{t} h_{t+1}$. So the risk-free rate can be included in the two-way breakdown as follows:

$$
y_{t+1}-E_{t} y_{t+1}=-\sum_{i=1}^{\infty} \rho^{i}\left(E_{t+1}-E_{t}\right)\left(y_{t+1+i}+r_{t+1+i}\right)+\sum_{i=0}^{\infty} \rho^{i}\left(E_{t+1}-E_{t}\right) \Delta d_{t+1+i}
$$

or as

$$
\begin{aligned}
y_{t+1}-E_{t} y_{t+1}= & -\sum_{i=1}^{\infty} \rho^{i}\left(E_{t+1}-E_{t}\right) y_{t+1+i}- \\
& \sum_{i=1}^{\infty} \rho^{i}\left(E_{t+1}-E_{t}\right) r_{t+1+i}+\sum_{i=0}^{\infty} \rho^{i}\left(E_{t+1}-E_{t}\right) \Delta d_{t+1+i} .
\end{aligned}
$$

Again, because $E_{t} r_{t+1}=r_{t+1}$, it doesn't matter whether the summation involving the $r$ s begins at 0 or 1 . Finally, letting $e_{t+1}^{y}$ represent the "excess return surprise" and replacing the summations with the corresponding $\tilde{e} s$ yields (10). 


\section{References}

Bernanke, Ben S., \& Gertler, Mark. 1999. Monetary Policy and Asset Price Volatility. Federal Reserve Bank of Kansas City Economic Review, 17-51.

Boyd, John H., Jagannathan, Ravi, \& Hu, Jian. 2001 (Dec.). The Stock Market's Reaction to Unemployment News: Why Bad News Is Usually Good For Stocks. Working Paper 8092. NBER.

Brandt, Michael W., \& Wang, Kevin Q. 2003. Time-varying risk aversion and unexpected inflation. Journal of Monetary Economics, 1457-1498.

Campbell, John Y. 1991. A Variance Decomposition for Stock Returns. The Economic Journal, 101(Mar.), 157-79.

Campbell, John Y., \& Ammer, John. 1993. What Moves the Stock and Bond Markets? A Variance Decomposition for Long-Term Asset Returns. Journal of Finance, 48(Mar.), $3-37$.

Campbell, John Y., \& Cochrane, John. 1999. By Force of Habit: A Consumption-Based Explanation of Aggregate Stock Market Behavior. Journal of Political Economy, 107, 205-51.

Campbell, John Y., \& Shiller, Robert J. 1988. The Dividend-Price Ratio and Expectations of Future Dividends and Discount Factors. Review of Financial Studies, 1, 195-228.

Campbell, John Y., \& Vuolteenaho, Tuomo. 2003. Bad Beta, Good Beta. Manuscript, Harvard University.

Cochrane, John H., \& Piazzesi, Monika. 2002 (Mar.). The Fed and Interest Rates: A HighFrequency Identification. Working Paper 8839. NBER.

Craine, Roger, \& Martin, Vance. 2003. Monetary Policy Shocks and Security Market Responses. Manuscript, University of California at Berkeley.

D’Amico, Stefania, \& Farka, Mira. 2003. The Fed and the Stock Market: A Proxy and Instrumental Variable Identification. Manuscript, Columbia University.

Evans, Charles L., \& Kuttner, Kenneth N. 1998 (Dec.). Can VARs Describe Monetary Policy? Working Paper 98-19. Federal Reserve Bank of Chicago.

Fama, Eugene F., \& French, Kenneth R. 1988. Permanent and Temporary Components of Stock Prices. Journal of Political Economy, 96, 246-273. 
Faust, Jon, Swanson, Eric, \& Wright, Jonathan H. 2002 (Feb.). Identifying VARs Based on High Frequency Futures Data. International Finance Discussion Paper 2002-720. Board of Governors of the Federal Reserve System.

Faust, Jon, Swanson, Eric, \& Wright, Jonathan. 2003. Do Federal Reserve Policy Surprises Reveal Private Information About the Economy? Manuscript, Board of Governors of the Federal Reserve System.

Fuhrer, Jeff, \& Tootell, Geoffrey. 2003. Eyes on the Prize: How Did the Fed Respond to the Stock Market? Manuscript, Federal Reserve Bank of Boston.

Goto, Shingo, \& Valkanov, Rossen. 2000. The Fed's Effect on Excess Returns and Inflation is Much Bigger Than You Think. Manuscript, UCLA Anderson School.

Guo, Hui. 2002. Stock Prices, Firm Size, and Changes in the Federal Funds Rate Target. Manuscript, Federal Reserve Bank of Saint Louis.

Gürkaynak, Refet S., Sack, Brian P., \& Swanson, Eric T. 2002. Market-Based Measures of Monetary Policy Expectations. Manuscript, Board of Governors of the Federal Reserve System.

Gürkaynak, Refet S., Sack, Brian P., \& Swanson, Eric T. 2004. The Effects of Monetary Policy on Asset Prices: An Intraday Event-Study Analysis. Manuscript, Board of Governors of the Federal Reserve System.

Hilton, Spence. 1994. Expected Federal Funds Rate Data. Unpublished memorandum, Federal Reserve Bank of New York, June 17.

Jensen, Gerald R., \& Mercer, Jeffrey M. 1998. Monetary Policy and the Cross-Section of Expected Stock Returns. Manuscript, Northeastern Illinois University.

Jensen, Gerald R., Johnson, R. R., \& Mercer, Jeffrey M. 1996. Business Conditions, Monetary Policy, and Expected Security Returns. Journal of Financial Economics, 40, 213-37.

Krueger, Joel T., \& Kuttner, Kenneth N. 1996. The Fed Funds Futures Rate as a Predictor of Federal Reserve Policy. Journal of Futures Markets, 16(8), 865-879.

Kuttner, Kenneth N. 2001. Monetary policy surprises and interest rates: Evidence from the Fed funds futures market. Journal of Monetary Economics, 47(3), 523-44.

Kuttner, Kenneth N. 2003. Dating Changes in the Federal Funds Rate, 1989-92. Manuscript, Federal Reserve Bank of New York. 
Nelson, Charles R., \& Kim, Myung J. 1993. Predictable Stock Returns: The Role of Small Sample Bias. Journal of Finance, 48(June), 641-61.

Patelis, Alex D. 1997. Stock Return Predictability and the Role of Monetary Policy. Journal of Finance, 52(Dec.), 1951-72.

Poole, William, Rasche, Robert, \& Thornton, Daniel. 2002. Market Anticipations of Monetary Policy Actions. Federal Reserve Bank of St. Louis Review, 84, 65-93.

Rigobon, Roberto, \& Sack, Brian. 2002 (Jan.). The Impact of Monetary Policy on Asset Prices. Finance and Economics Discussion Series 2002-4. Board of Governors of the Federal Reserve System.

Rigobon, Roberto, \& Sack, Brian. 2003. Measuring the Reaction of Monetary Policy to the Stock Market. Quarterly Journal of Economics, 118, 639-70.

Romer, Christina D., \& Romer, David H. 2000. Federal Reserve Information and the Behavior of Interest Rates. American Economic Review, 90, 429-457.

Rudebusch, Glenn. 1995. Federal Reserve Interest Rate Targeting, Rational Expectations, and the Term Structure. Journal of Monetary Economics, 35(2), 245-274.

Thorbecke, William. 1997. On Stock Market Returns and Monetary Policy. Journal of Finance, 52(June), 635-54. 
Table 1

\section{Descriptive statistics}

The table reports selected descriptive statistics for federal funds rate surprises and the CRSP value-weighted equity return over the samples given in the column headings. All statistics exclude the 17 September 2001 observation.

\begin{tabular}{lcc}
\hline & $\begin{array}{c}\text { May 1989- } \\
\text { January 1994 }\end{array}$ & $\begin{array}{c}\text { February 1994- } \\
\text { December 2002 }\end{array}$ \\
\hline $\begin{array}{l}\text { Number of events: rate changes } \\
\text { and FOMC meetings }\end{array}$ & 55 & 76 \\
$\begin{array}{l}\text { Standard deviation of } \\
\text { federal funds surprise, basis points } \\
\begin{array}{l}\text { Standard deviation of equity return } \\
\text { on event days, } \%\end{array}\end{array}$ & 10.4 & 9.5 \\
$\begin{array}{l}\text { Standard deviation of equity return } \\
\text { on non-event days, \% } \\
\begin{array}{l}\text { Proportion of rate changes } \\
\text { taking place at FOMC meetings }\end{array}\end{array}$ & 0.80 & 1.26 \\
\hline
\end{tabular}


Table 2

\section{The response of equity prices to federal funds rate changes}

The table reports the results from regressions of the one-day CRSP value-weighted equity return on changes in the federal funds rate (columns a and c), and on the surprise and expected components of the funds rate change (columns b and d). All variables are expressed in percentage terms. The full sample consists of the 55 target rate changes and the 77 FOMC meeting dates over the period from June 1989 through December 2002, excluding the 17 September 2001 observation, for a total of 131 observations. The outliers excluded from the regressions in columns $\mathrm{c}$ and $\mathrm{d}$ correspond to the six observations with influence statistics in excess of 0.3 , leaving 125 usable observations. Parentheses contain $t$-statistics, calculated using heteroskedasticity-consistent estimates of the standard errors.

\begin{tabular}{|c|c|c|c|c|}
\hline \multirow[b]{2}{*}{ Regressor } & \multicolumn{2}{|c|}{ Full sample } & \multicolumn{2}{|c|}{ Excluding outliers } \\
\hline & (a) & (b) & (c) & (d) \\
\hline Intercept & $\begin{array}{c}0.23 \\
(2.58)\end{array}$ & $\begin{array}{c}0.12 \\
(1.35)\end{array}$ & $\begin{array}{c}0.17 \\
(2.14)\end{array}$ & $\begin{array}{c}0.11 \\
(1.37)\end{array}$ \\
\hline Raw funds rate change & $\begin{array}{c}-0.61 \\
(1.06)\end{array}$ & $\ldots$ & $\begin{array}{c}-0.11 \\
(0.31)\end{array}$ & $\ldots$ \\
\hline Expected change & $\ldots$ & $\begin{array}{c}1.04 \\
(2.17)\end{array}$ & $\ldots$ & $\begin{array}{c}0.67 \\
(1.62)\end{array}$ \\
\hline Surprise change & $\cdots$ & $\begin{array}{c}-4.68 \\
(3.03)\end{array}$ & $\cdots$ & $\begin{array}{c}-2.55 \\
(2.79)\end{array}$ \\
\hline$\overline{R^{2}}$ & 0.007 & 0.171 & -0.007 & 0.049 \\
\hline
\end{tabular}


Table 3

Tests for subsample stability and endogeneity

The table reports the results from regressions of the one-day CRSP value-weighted equity return on the surprise and expected components of the change in the federal funds rate, all expressed in percentage terms. The post-1994 dummy is set to 1 for observations beginning with 4 February 1994. The employment dummy is set to 1 for pre-1994 observations when a change in the target funds rate coincided with an employment release. The full and nooutlier samples are the same as those used for the results appearing in Table 2. Parentheses contain $t$-statistics, calculated using heteroskedasticity-consistent estimates of the standard errors.

\begin{tabular}{|c|c|c|c|c|}
\hline \multirow[b]{2}{*}{ Regressor } & \multicolumn{2}{|c|}{ Full sample } & \multicolumn{2}{|c|}{ Excluding outliers } \\
\hline & (a) & (b) & (c) & (d) \\
\hline Intercept & $\begin{array}{c}0.16 \\
(1.80)\end{array}$ & $\begin{array}{c}0.16 \\
(1.76)\end{array}$ & $\begin{array}{c}0.12 \\
(1.43)\end{array}$ & $\begin{array}{c}0.12 \\
(1.43)\end{array}$ \\
\hline Expected change & $\begin{array}{c}1.09 \\
(2.26)\end{array}$ & $\begin{array}{c}1.09 \\
(2.24)\end{array}$ & $\begin{array}{c}0.69 \\
(1.68)\end{array}$ & $\begin{array}{c}0.69 \\
(1.67)\end{array}$ \\
\hline Surprise change & $\begin{array}{c}-1.25 \\
(1.14)\end{array}$ & $\begin{array}{c}-2.55 \\
(1.70)\end{array}$ & $\begin{array}{c}-2.29 \\
(2.28)\end{array}$ & $\begin{array}{c}-3.57 \\
(3.77)\end{array}$ \\
\hline \multicolumn{5}{|l|}{ Surprise change $\times$} \\
\hline post-1994 & $\begin{array}{c}-6.87 \\
(3.59)\end{array}$ & $\begin{array}{c}-5.58 \\
(2.61)\end{array}$ & $\begin{array}{c}-0.78 \\
(0.45)\end{array}$ & $\begin{array}{c}0.50 \\
(0.29)\end{array}$ \\
\hline employment report & $\ldots$ & $\begin{array}{c}2.67 \\
(1.82)\end{array}$ & $\ldots$ & $\begin{array}{c}3.33 \\
(2.55)\end{array}$ \\
\hline $\bar{R}^{2}$ & 0.280 & 0.283 & 0.042 & 0.054 \\
\hline
\end{tabular}




\section{Table 4}

\section{Tests for asymmetries}

The table reports the results from regressions of the one-day CRSP value-weighted equity return on the surprise and expected components of the change in the federal funds rate, all expressed in percentage terms. The positive surprise dummy is set to 1 when the surprise change in the funds rate is greater than zero. The no rate change and positive rate change dummies equal 1 when the funds rate target is unchanged or increased. The FOMC meeting dummy is set to 1 for those observations coinciding with FOMC meetings. The reversal dummy equals 1 for rate changes that reverse the direction of the previous change. The post-1994 dummy is set to 1 for observations beginning with 4 February 1994. The employment dummy is set to 1 for pre-1994 observations when a change in the target funds rate coincided with an employment release. The full and no-outlier samples are the same as those used for the results appearing in Table 2. Parentheses contain $t$-statistics, calculated using heteroskedasticity-consistent estimates of the standard errors.

\begin{tabular}{|c|c|c|c|c|c|c|}
\hline \multirow[b]{2}{*}{ Regressor } & \multicolumn{3}{|c|}{ Full sample } & \multicolumn{3}{|c|}{ Excluding outliers } \\
\hline & (a) & (b) & (c) & (d) & (e) & (f) \\
\hline Intercept & $\begin{array}{c}-0.02 \\
(0.17)\end{array}$ & $\begin{array}{c}0.12 \\
(1.34)\end{array}$ & $\begin{array}{c}0.14 \\
(1.72)\end{array}$ & $\begin{array}{c}0.12 \\
(1.32)\end{array}$ & $\begin{array}{c}0.12 \\
(1.42)\end{array}$ & $\begin{array}{c}0.13 \\
(1.63)\end{array}$ \\
\hline Expected change & $\begin{array}{c}0.84 \\
(1.58)\end{array}$ & $\begin{array}{c}1.56 \\
(3.24)\end{array}$ & $\begin{array}{c}1.03 \\
(2.24)\end{array}$ & $\begin{array}{c}0.72 \\
(1.67)\end{array}$ & $\begin{array}{c}0.97 \\
(2.00)\end{array}$ & $\begin{array}{c}0.72 \\
(1.76)\end{array}$ \\
\hline Surprise change & $\begin{array}{c}-7.57 \\
(4.67)\end{array}$ & $\begin{array}{c}-8.34 \\
(5.73)\end{array}$ & $\begin{array}{c}-3.97 \\
(2.98)\end{array}$ & $\begin{array}{c}-3.26 \\
(3.30)\end{array}$ & $\begin{array}{c}-4.49 \\
(4.91)\end{array}$ & $\begin{array}{c}-3.67 \\
(3.14)\end{array}$ \\
\hline \multicolumn{7}{|l|}{ Surprise change $\times$} \\
\hline employment & $\begin{array}{c}7.05 \\
(4.43)\end{array}$ & $\begin{array}{c}8.11 \\
(5.26)\end{array}$ & $\begin{array}{c}2.54 \\
(1.47)\end{array}$ & $\begin{array}{c}3.05 \\
(2.36)\end{array}$ & $\begin{array}{c}4.14 \\
(3.19)\end{array}$ & $\begin{array}{c}3.46 \\
(2.35)\end{array}$ \\
\hline positive surprise & $\begin{array}{c}7.39 \\
(1.59)\end{array}$ & $\ldots$ & $\ldots$ & $\begin{array}{c}-0.34 \\
(0.10)\end{array}$ & $\ldots$ & $\ldots$ \\
\hline no rate change & $\ldots$ & $\begin{array}{l}10.42 \\
(3.81)\end{array}$ & $\ldots$ & $\ldots$ & $\begin{array}{c}4.00 \\
(2.25)\end{array}$ & .. \\
\hline positive rate change & $\ldots$ & $\begin{array}{c}3.05 \\
(0.76)\end{array}$ & $\ldots$ & $\ldots$ & $\begin{array}{c}0.58 \\
(0.15)\end{array}$ & .. \\
\hline FOMC meeting & .. & $\ldots$ & $\begin{array}{c}4.25 \\
(2.75)\end{array}$ & $\cdots$ & $\ldots$ & $\begin{array}{c}0.67 \\
(0.39)\end{array}$ \\
\hline reversal & .. & $\ldots$ & $\begin{array}{c}-6.33 \\
(3.09)\end{array}$ & $\cdots$ & $\ldots$ & $\begin{array}{r}-17.62 \\
(4.08)\end{array}$ \\
\hline post-1994 & $\ldots$ & $\ldots$ & $\begin{array}{c}-4.61 \\
(2.48)\end{array}$ & $\ldots$ & $\ldots$ & $\begin{array}{c}0.80 \\
(0.44)\end{array}$ \\
\hline$\overline{R^{2}}$ & 0.260 & 0.323 & 0.369 & 0.053 & 0.065 & 0.098 \\
\hline
\end{tabular}




\section{Table 5}

\section{The response of interest rate expectations to federal funds rate surprises}

The table reports the results from regressions of the one-day change in the three-monthahead federal funds futures rate on the surprise and expected components of the change in the federal funds rate, all expressed in percentage terms. The no rate change and positive rate change dummies equal 1 when the funds rate target is unchanged or increased. The FOMC meeting dummy is set to 1 for those observations coinciding with FOMC meetings. The reversal dummy equals 1 for rate changes that reverse the direction of the previous change. The full and no-outlier samples are the same as those used for the results appearing in Table 2. Parentheses contain $t$-statistics, calculated using heteroskedasticity-consistent estimates of the standard errors.

\begin{tabular}{|c|c|c|c|c|}
\hline Regressor & (a) & (b) & (c) & (d) \\
\hline Intercept & $\begin{array}{c}-0.01 \\
(1.46)\end{array}$ & $\begin{array}{c}-0.01 \\
(1.55)\end{array}$ & $\begin{array}{c}-0.01 \\
(1.34)\end{array}$ & $\begin{array}{c}-0.01 \\
(1.40)\end{array}$ \\
\hline Expected change & $\begin{array}{c}0.07 \\
(2.10)\end{array}$ & $\begin{array}{c}0.05 \\
(1.32)\end{array}$ & $\begin{array}{c}0.07 \\
(2.29)\end{array}$ & $\begin{array}{c}0.07 \\
(2.08)\end{array}$ \\
\hline Surprise change & $\begin{array}{c}0.65 \\
(13.37)\end{array}$ & $\begin{array}{c}0.70 \\
(14.71)\end{array}$ & $\begin{array}{c}0.73 \\
(14.54)\end{array}$ & $\begin{array}{c}0.66 \\
(12.83)\end{array}$ \\
\hline \multicolumn{5}{|l|}{ Surprise change $\times$} \\
\hline no rate change & $\ldots$ & $\begin{array}{c}-0.36 \\
(3.24)\end{array}$ & $\ldots$ & $\ldots$ \\
\hline FOMC meeting & $\ldots$ & $\ldots$ & $\begin{array}{c}-0.21 \\
(2.07)\end{array}$ & $\cdots$ \\
\hline reversal & $\ldots$ & $\ldots$ & $\ldots$ & $\begin{array}{c}-0.12 \\
(2.24)\end{array}$ \\
\hline $\bar{R}^{2}$ & 0.726 & 0.745 & 0.744 & 0.727 \\
\hline
\end{tabular}


Table 6

\section{The stock market response to level versus timing surprises}

The table reports the results from regressions of the one-day CRSP value-weighted equity return on the surprise and expected components of the change in the federal funds rate, and the timing surprise, all expressed in percentage terms. The timing surprise is defined as the difference between the change in the three-month-ahead futures rate and the current month's surprise. The full and no-outlier samples are the same as those used for the results appearing in Table 2. Parentheses contain $t$-statistics, calculated using heteroskedasticityconsistent estimates of the standard errors.

\begin{tabular}{|c|c|c|c|c|}
\hline \multirow[b]{2}{*}{ Regressor } & \multicolumn{2}{|c|}{ Full sample } & \multicolumn{2}{|c|}{ Excluding outliers } \\
\hline & (a) & (b) & (c) & (d) \\
\hline Intercept & $\begin{array}{c}0.12 \\
(1.35)\end{array}$ & $\begin{array}{c}0.09 \\
(1.09)\end{array}$ & $\begin{array}{c}0.11 \\
(1.37)\end{array}$ & $\begin{array}{c}0.09 \\
(1.11)\end{array}$ \\
\hline Expected change & $\begin{array}{c}1.05 \\
(2.17)\end{array}$ & $\begin{array}{c}1.34 \\
(2.92)\end{array}$ & $\begin{array}{c}0.67 \\
(1.62)\end{array}$ & $\begin{array}{c}0.94 \\
(2.46)\end{array}$ \\
\hline Surprise change & $\begin{array}{c}-4.68 \\
(3.03)\end{array}$ & $\begin{array}{c}-6.20 \\
(3.80)\end{array}$ & $\begin{array}{c}-2.55 \\
(2.79)\end{array}$ & $\begin{array}{c}-4.17 \\
(4.20)\end{array}$ \\
\hline Timing surprise & $\ldots$ & $\begin{array}{c}-4.29 \\
(2.20)\end{array}$ & $\ldots$ & $\begin{array}{c}-4.27 \\
(3.25)\end{array}$ \\
\hline $\begin{array}{l}\text { Effect of "pure" } \\
\text { timing surprise }\end{array}$ & $\ldots$ & $\begin{array}{c}-1.91 \\
(0.91)\end{array}$ & $\cdots$ & $\begin{array}{c}0.09 \\
(0.08)\end{array}$ \\
\hline$\overline{R^{2}}$ & 0.171 & 0.192 & 0.049 & 0.085 \\
\hline
\end{tabular}


Table 7

The impact of economic news on federal funds rate surprises

The table reports the results from regressions of the monthly federal funds rate surprise on the unexpected components of the data releases listed in the row headings, over the sample indicated in the column headings. Survey data gathered by Money Market Services are used to calculate the data surprises. Asterisks denote statistical significance based on heteroskedasticity-consistent estimates of the standard errors: *** for the 0.01 level, ** for the 0.05 level, and $*$ for the 0.01 level.

\begin{tabular}{lccc}
\hline & & \multicolumn{2}{c}{ Subsample } \\
\cline { 3 - 4 } Data surprise & Full sample & $5 / 89-9 / 92$ & $2 / 94-12 / 02$ \\
\hline Headline CPI & 0.016 & -0.124 & -0.010 \\
Core CPI & -0.058 & -0.012 & 0.152 \\
Headline PPI & 0.001 & -0.027 & -0.024 \\
Core PPI & $-0.085^{* *}$ & $-0.304^{* * *}$ & -0.022 \\
Nonfarm payrolls & $0.203^{* *}$ & $0.624^{* * *}$ & -0.009 \\
Industrial production & $0.069^{*}$ & 0.136 & 0.028 \\
Retail sales & $-0.031^{* *}$ & -0.061 & $-0.035^{* * *}$ \\
Retail sales, x autos & 0.023 & 0.093 & 0.021 \\
$R^{2}$ & 0.128 & 0.454 & 0.087 \\
$R^{2}$ & 0.082 & 0.304 & 0.012 \\
\hline
\end{tabular}


Table 8

\section{The monthly response of equity prices to federal funds rate surprises}

The table reports the results from regressions of the one-month CRSP value-weighted equity return on the surprise and expected components of the one-month change in the federal funds rate, all expressed in percentage terms. The full sample includes 164 monthly observations spanning May 1989 through December 2002. The no-outlier sample contains 154 observations. Parentheses contain $t$-statistics, calculated using heteroskedasticityconsistent estimates of the standard errors.

\begin{tabular}{|c|c|c|c|c|c|}
\hline \multirow[b]{2}{*}{ Regressor } & \multirow{2}{*}{$\begin{array}{c}\text { Full } \\
\text { sample } \\
\text { (a) }\end{array}$} & \multirow{2}{*}{$\begin{array}{c}\text { No } \\
\text { outliers } \\
\text { (b) }\end{array}$} & \multicolumn{3}{|c|}{ Tests for asymmetries } \\
\hline & & & (c) & (d) & (e) \\
\hline Intercept & $\begin{array}{c}0.13 \\
(0.32)\end{array}$ & $\begin{array}{c}-0.03 \\
(0.09)\end{array}$ & $\begin{array}{c}-0.01 \\
(0.02)\end{array}$ & $\begin{array}{c}-0.07 \\
(0.16)\end{array}$ & $\begin{array}{c}0.10 \\
(0.24)\end{array}$ \\
\hline Expected change & $\begin{array}{c}-1.11 \\
(0.37)\end{array}$ & $\begin{array}{c}0.96 \\
(0.35)\end{array}$ & $\begin{array}{r}-1.07 \\
(0.36)\end{array}$ & $\begin{array}{c}-2.72 \\
(0.72)\end{array}$ & $\begin{array}{r}-1.09 \\
(0.36)\end{array}$ \\
\hline Surprise change & $\begin{array}{r}-11.43 \\
(3.95)\end{array}$ & $\begin{array}{r}-14.26 \\
(5.43)\end{array}$ & $\begin{array}{r}-12.46 \\
(3.69)\end{array}$ & $\begin{array}{r}-11.01 \\
(3.46)\end{array}$ & $\begin{array}{r}-10.49 \\
(2.53)\end{array}$ \\
\hline \multicolumn{6}{|l|}{ Surprise change $\times$} \\
\hline positive surprise & $\cdots$ & $\ldots$ & $\begin{array}{c}6.82 \\
(0.63)\end{array}$ & $\ldots$ & $\cdots$ \\
\hline no rate change & $\cdots$ & $\ldots$ & & $\begin{array}{c}-4.88 \\
(0.75)\end{array}$ & $\ldots$ \\
\hline positive rate change & $\ldots$ & $\ldots$ & $\ldots$ & $\begin{array}{c}6.59 \\
(0.52)\end{array}$ & $\ldots$ \\
\hline reversal & $\ldots$ & $\ldots$ & $\ldots$ & $\ldots$ & $\begin{array}{c}3.52 \\
(0.50)\end{array}$ \\
\hline post-1994 & $\ldots$ & $\ldots$ & $\ldots$ & $\ldots$ & $\begin{array}{r}-3.77 \\
(0.50)\end{array}$ \\
\hline Employment surprise & $\ldots$ & $\ldots$ & $\ldots$ & $\ldots$ & $\begin{array}{c}-0.69 \\
(0.10)\end{array}$ \\
\hline$\overline{R^{2}}$ & 0.065 & 0.096 & 0.061 & 0.056 & 0.049 \\
\hline Standard error & 4.28 & 3.85 & 4.30 & 4.30 & 4.31 \\
\hline Durbin-Watson statistic & 2.02 & 2.09 & 2.02 & 2.02 & 2.03 \\
\hline
\end{tabular}


Table 9

\section{The response of Fama-French industry portfolios to federal funds rate surprises}

The table reports the results from regressions of the one-month returns on the Fama-French industry portfolios indicated in the row headings on the surprise and expected components of the one-month change in the federal funds rate, all expressed in percentage terms. The regressions also include an intercept, whose coefficient is not reported. The full sample includes 164 monthly observations spanning May 1989 through December 2002. Parentheses contain $t$-statistics, calculated using heteroskedasticity-consistent estimates of the standard errors.

\begin{tabular}{|c|c|c|c|c|c|c|}
\hline \multirow[b]{2}{*}{ Index } & \multicolumn{2}{|c|}{ Response to federal funds rate changes: } & \multirow[b]{2}{*}{$\bar{R}^{2}$} & \multirow[b]{2}{*}{ SE } & \multirow[b]{2}{*}{ DW } & \multirow{2}{*}{$\begin{array}{c}\text { Market } \\
\text { beta }\end{array}$} \\
\hline & anticipated & $\overline{\text { unanticipated }}$ & & & & \\
\hline CRSP value weighted & $\begin{array}{r}-1.11 \\
(0.37)\end{array}$ & $\begin{array}{r}-11.43 \\
(3.95)\end{array}$ & 0.065 & 4.28 & 2.02 & 1 \\
\hline Nondurables & $\begin{array}{c}-0.85 \\
(0.25)\end{array}$ & $\begin{array}{c}-9.65 \\
(2.88)\end{array}$ & 0.046 & 4.17 & 2.00 & 0.60 \\
\hline Durables & $\begin{array}{c}-1.47 \\
(0.38)\end{array}$ & $\begin{array}{r}-12.45 \\
(3.04)\end{array}$ & 0.048 & 5.56 & 1.97 & 1.02 \\
\hline Manufacturing & $\begin{array}{r}-2.02 \\
(0.61)\end{array}$ & $\begin{array}{r}-8.82 \\
(2.81)\end{array}$ & 0.035 & 4.26 & 2.03 & 0.85 \\
\hline Energy & $\begin{array}{c}0.20 \\
(1.02)\end{array}$ & $\begin{array}{c}-4.03 \\
(1.24)\end{array}$ & -0.003 & 4.71 & 2.12 & 0.55 \\
\hline High tech & $\begin{array}{c}0.06 \\
(0.01)\end{array}$ & $\begin{array}{r}-14.73 \\
(2.72)\end{array}$ & 0.025 & 8.22 & 2.00 & 1.61 \\
\hline Telecommunications & $\begin{array}{c}0.35 \\
(0.60)\end{array}$ & $\begin{array}{r}-16.10 \\
(3.31)\end{array}$ & 0.065 & 6.16 & 1.85 & 1.16 \\
\hline Wholesale/retail & $\begin{array}{c}-4.75 \\
(1.47)\end{array}$ & $\begin{array}{r}-11.97 \\
(3.64)\end{array}$ & 0.056 & 4.85 & 1.95 & 0.90 \\
\hline Health care & $\begin{array}{c}-1.04 \\
(0.29)\end{array}$ & $\begin{array}{c}-8.04 \\
(1.80)\end{array}$ & 0.017 & 4.96 & 2.15 & 0.72 \\
\hline Utilities & $\begin{array}{r}-1.24 \\
(0.48)\end{array}$ & $\begin{array}{r}-5.42 \\
(1.55)\end{array}$ & 0.006 & 4.21 & 1.97 & 0.32 \\
\hline Other & $\begin{array}{c}-1.21 \\
(0.35)\end{array}$ & $\begin{array}{r}-11.08 \\
(3.61)\end{array}$ & 0.051 & 4.62 & 2.09 & 0.92 \\
\hline
\end{tabular}




\section{Table 10}

\section{A variance decomposition of excess equity returns}

The table reports the decomposition of the variance of the current excess equity returns into the variances of revisions in expectations of dividends, real interest rates, future excess returns, and the covariances between these three components. The excess equity return is the difference between the CRSP value-weighted return and the one-month Treasury bill rate. A six-variable VAR(1) is used to construct forecasts of future real interest rates and excess returns. The VAR includes the excess equity return, the real interest rate, the relative bill rate (defined as the three-month bill rate minus its 12-month lagged moving average), the change in the three-month bill rate, the smoothed dividend price ratio, and the spread between the 10-year and one-month Treasury yields. Parentheses contain $t$ statistics, calculated using the delta method.

\begin{tabular}{|c|c|c|c|c|}
\hline & \multicolumn{2}{|c|}{ 1973-2002 } & \multicolumn{2}{|c|}{ 1989-2002 } \\
\hline & Total & Share $(\%)$ & Total & Share $(\%)$ \\
\hline Var(excess return) & 21.5 & & 19.0 & \\
\hline Var(dividends) & 5.3 & $\begin{array}{l}24.5 \\
(6.2)\end{array}$ & 6.1 & $\begin{array}{l}31.9 \\
(1.8)\end{array}$ \\
\hline Var(real rate) & 0.3 & $\begin{array}{c}1.4 \\
(2.4)\end{array}$ & 0.1 & $\begin{array}{c}0.6 \\
(1.5)\end{array}$ \\
\hline Var(future returns) & 16.4 & $\begin{array}{l}76.0 \\
(1.8)\end{array}$ & 7.2 & $\begin{array}{l}38.0 \\
(1.2)\end{array}$ \\
\hline$-2 \operatorname{Cov}($ dividends, real rate) & -0.4 & $\begin{array}{c}-2.1 \\
(0.8)\end{array}$ & -0.6 & $\begin{array}{r}-3.2 \\
(0.7)\end{array}$ \\
\hline$-2 \operatorname{Cov}($ dividends, future excess return) & 0.2 & $\begin{array}{c}1.0 \\
(0.0)\end{array}$ & 7.2 & $\begin{array}{r}-37.7 \\
(2.3)\end{array}$ \\
\hline $2 \operatorname{Cov}($ future excess return, real rate) & -0.2 & $\begin{array}{c}0.8 \\
(0.1)\end{array}$ & 1.0 & $\begin{array}{c}5.1 \\
(1.1)\end{array}$ \\
\hline $\bar{R}^{2}$ from excess return equation & & 0.040 & & -0.003 \\
\hline
\end{tabular}


Table 11

The impact of monetary policy on dividends, interest rates, and future returns

The table reports the impact of monetary policy surprises on the current excess equity return, and the discounted sums of future excess equity returns, current and future real interest rates, and current and future dividends. The six-variable VAR(1) used to construct real interest rate and excess equity return forecasts is estimated over the sample indicated in the column headings, and the contemporaneous response to the funds rate surprises is estimated on the February 1994 to December 2002 subsample. Parentheses contain $t$ statistics, calculated using the delta method.

\begin{tabular}{lcc}
\hline & \multicolumn{2}{c}{ Sample used for VAR } \\
\cline { 2 - 3 } & $1 / 73-12 / 02$ & $5 / 89-12 / 02$ \\
\hline Current excess return & -11.55 & -11.01 \\
& $(3.87)$ & $(3.72)$ \\
Future excess returns & 6.10 & 3.29 \\
& $(1.74)$ & $(1.10)$ \\
Real interest rate & 0.64 & 0.77 \\
& $(1.03)$ & $(1.87)$ \\
Dividends & -4.82 & -6.96 \\
& $(1.73)$ & $(2.35)$ \\
\hline
\end{tabular}




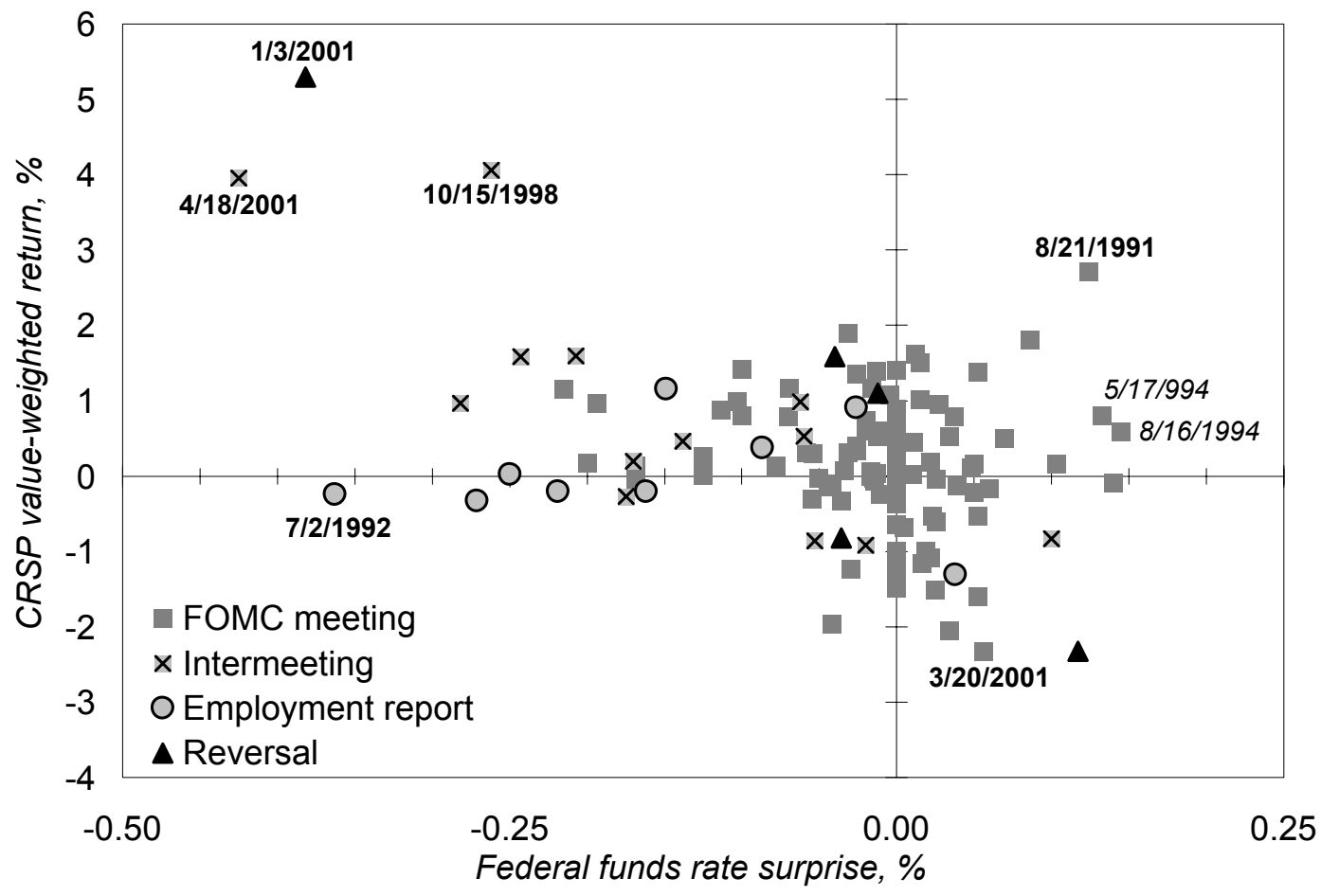

Figure 1. Federal funds rate surprises and equity returns, daily data. The figure is a scatterplot of one-day CRSP value-weighted equity returns against the surprise element of changes in the federal funds rate, for the 131 event days in the sample. Observations are distinguished by their association with FOMC meetings, intermeeting target rate changes, the release of employment reports, and changes in the direction of rate movements (reversals). The six observations with boldface date labels are those flagged as candidate outliers on the basis of regression influence statistics. The two observations with italicized date labels are those associated with unusual announcements by the FOMC. 


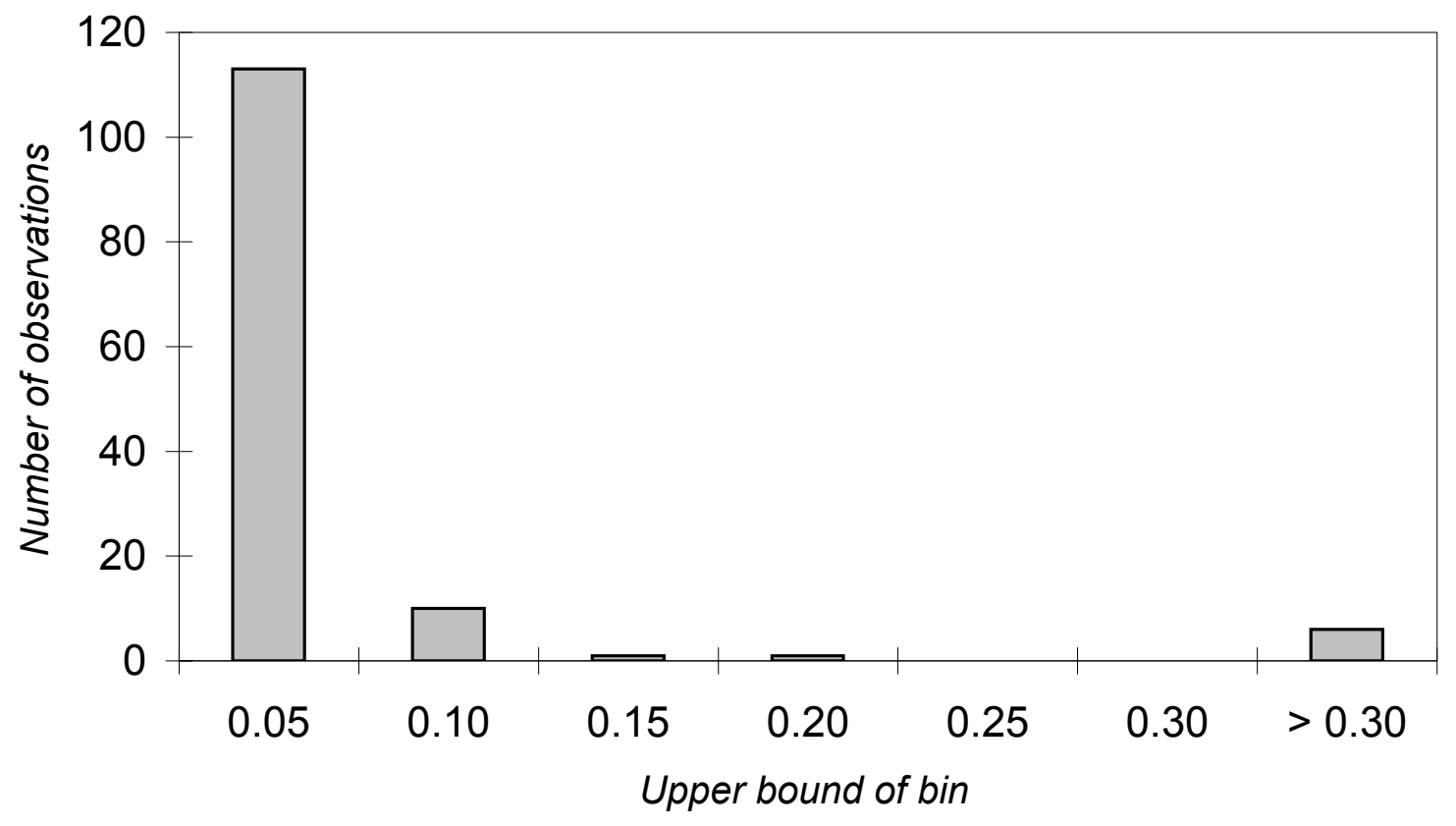

Figure 2. Distribution of regression influence statistics. The statistics are based on the changes in the estimated parameters from a regression of one-day CRSP value-weighted equity returns on the surprise and expected components of the federal funds rate change, dropping each observation in turn from the sample. 


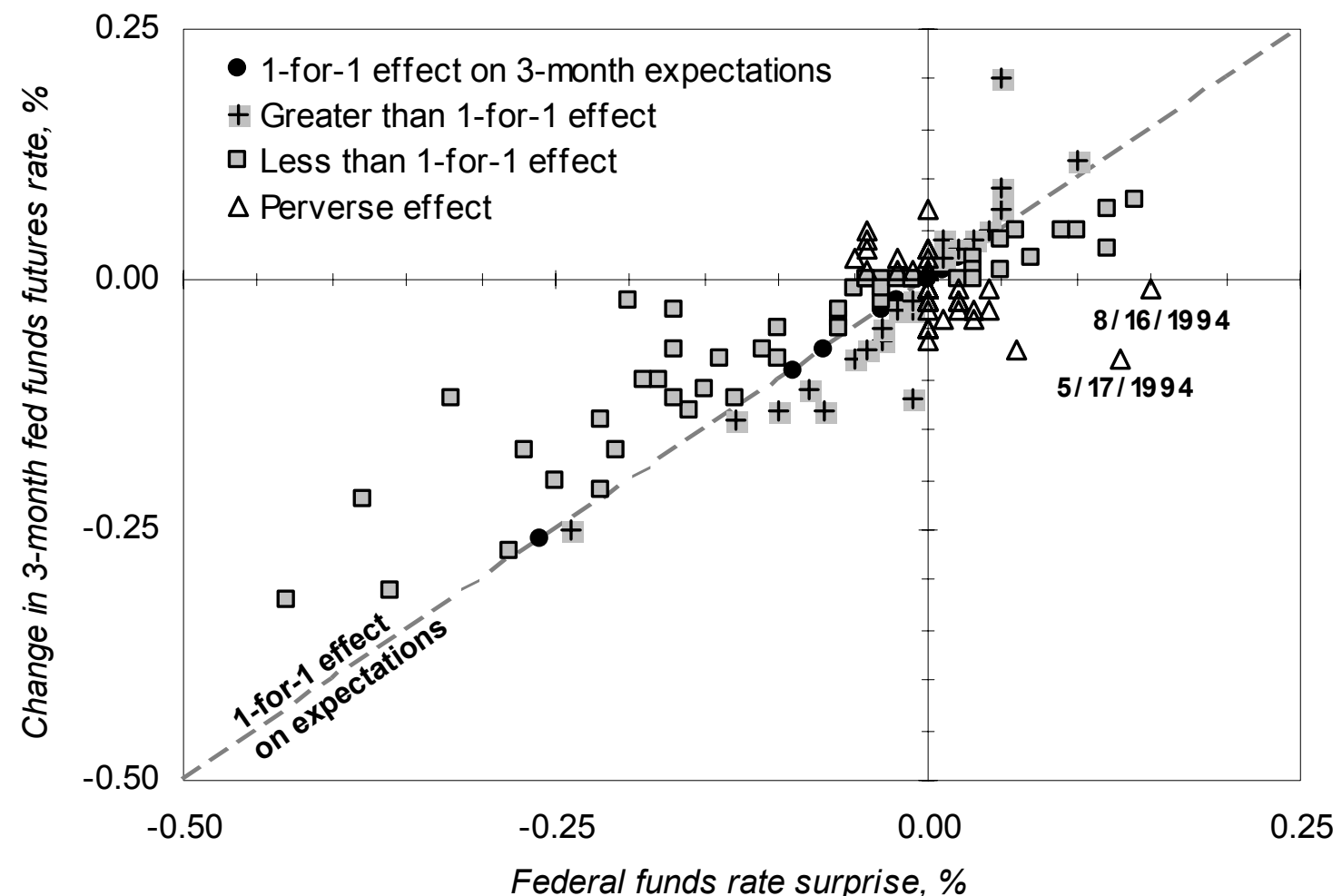

Figure 3. Federal funds rate surprises and funds rate expectations. The figure is a scatterplot of one-day changes in the three-month-ahead federal funds futures rate against the surprise element of changes in the federal funds rate, for the 131 event days in the sample. Observations are distinguished according to whether the reaction of three-monthahead expectations are greater than, less than, equal to, or opposite in sign from the federal funds rate surprise. The two observations with date labels are those associated with unusual announcements by the FOMC. 


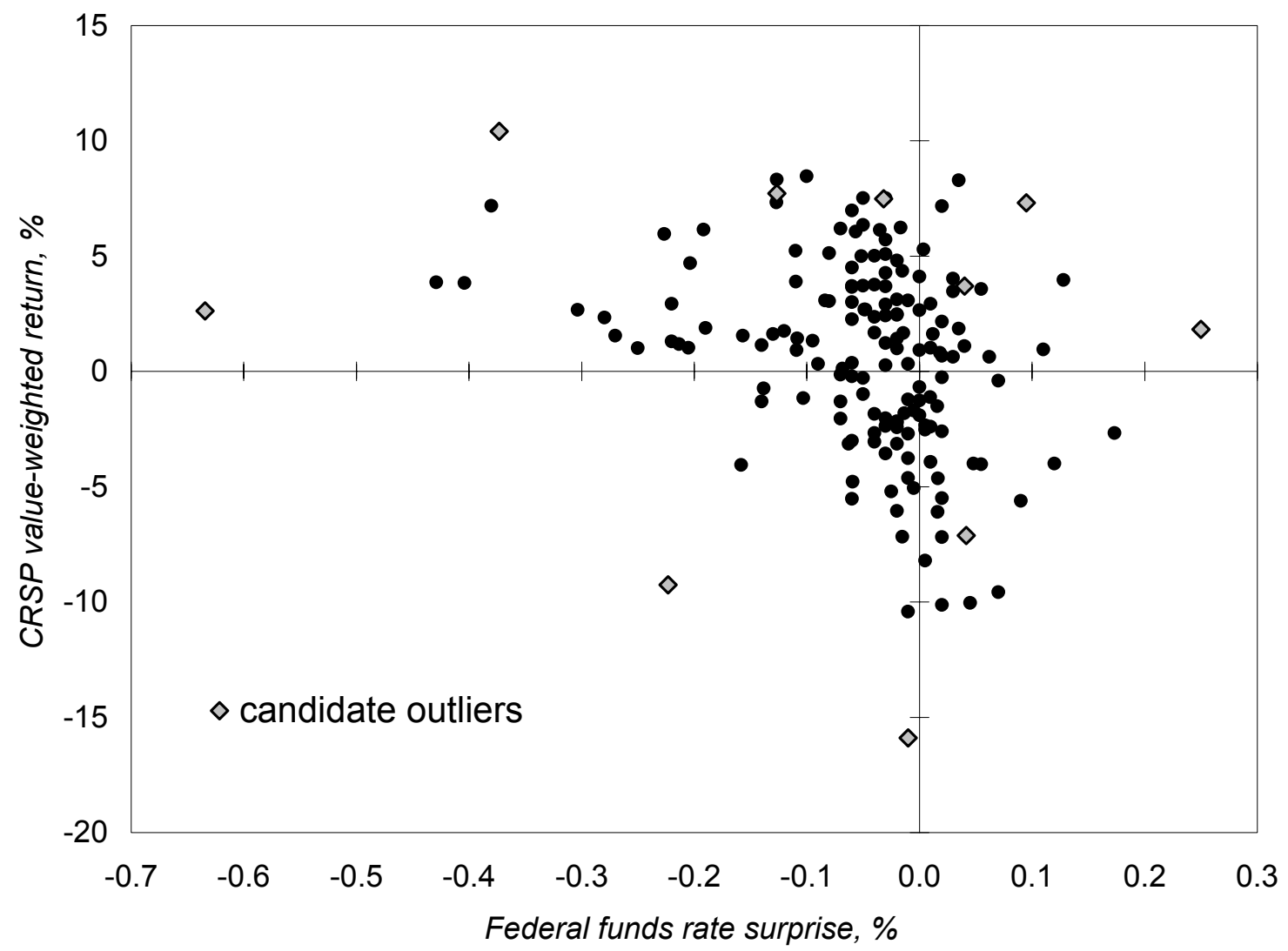

Figure 4. Federal funds rate surprises and equity returns, monthly data. The figure is a scatterplot of one-month CRSP value-weighted equity returns against the surprise element of changes in the federal funds rate, for the 164 months in the sample. Ten candidate outliers, identified on the basis of regression influence statistics, are distinguished. 


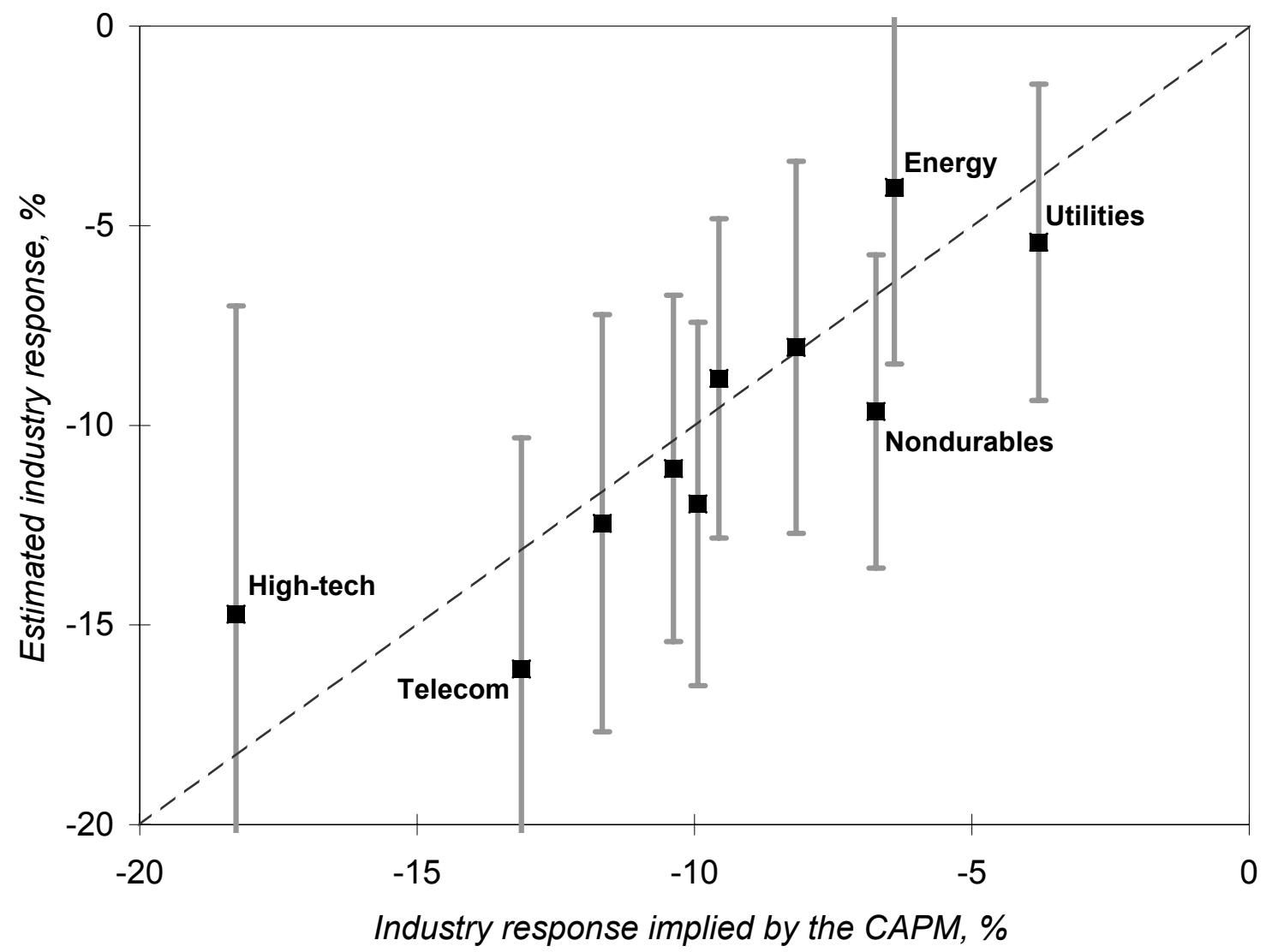

Figure 5. Estimated industry responses and CAPM implications. The figure depicts the one-month responses of the Fama-French industry portfolios to a one percentage point federal funds rate surprise. The values on the horizontal axis are the industry stock return responses implied by the CAPM. The vertical axis values are the estimated industry return responses reported in Table 9. The vertical lines represent the $80 \%$ confidence intervals associated with the estimated industry responses. 

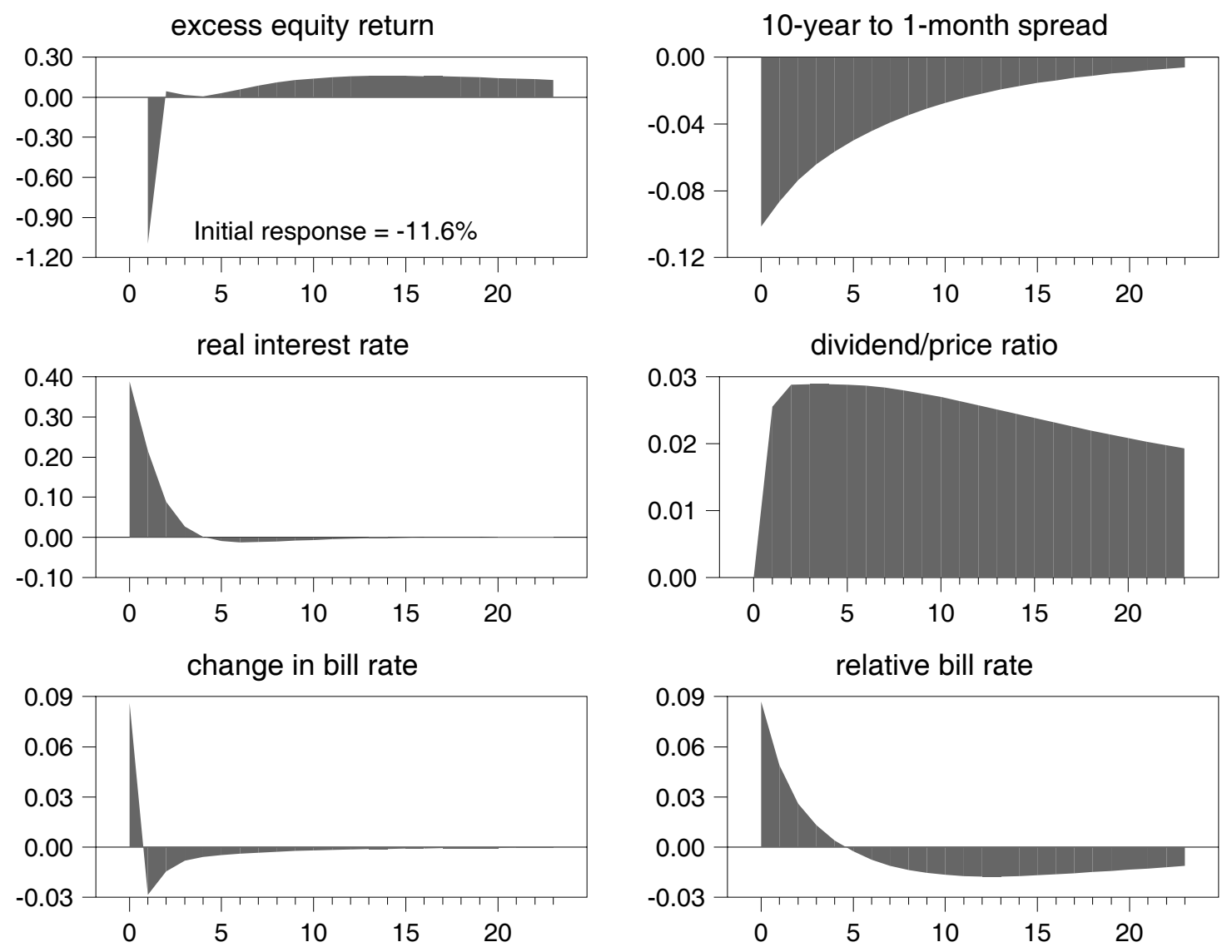

Months following federal funds rate surprise

Figure 6. The dynamic responses of excess equity returns, interest rates, and the dividend-price ratio to federal funds rate surprises. Each panel depicts the response of the indicated variable to a one percentage point federal funds rate surprise. The contemporaneous response to the funds rate surprises is estimated on the February 1994 to December 2002 subsample. A six-variable VAR(1), estimated over the 1973-2002 sample, is used to project the future path of each variable. Because of the large difference in scale, the initial excess return response is not shown. Each variable is experessed in monthly percentage terms. 